Revista de Derecho Público: Teoría y Método

\title{
CONSTITUCIÓN ECONÓMICA: UNA PROPUESTA AL DEBATE CONCEPTUAL
}

\author{
ECONOMIC CONSTITUTION: \\ A CONTRIBUTION TO THE CONCEPTUAL DEBATE
}

\author{
Daniela Dobre \\ Investigadora predoctoral FPU \\ Departamento de Derecho constitucional. Universidad de Granada
}

RESUMEN: A pesar de ser un término comúnmente empleado en la doctrina jurídica actual, el concepto de "Constitución económica" permite interpretaciones muy variadas, incluso contrapuestas. La presente contribución pretende esbozar las características esenciales de este concepto. Tras recorrer teóricamente la evolución de la Constitución económica (en especial, su origen ordoliberal y las definiciones alternativas más significativas en el nivel europeo), se proponen tres rasgos fundamentales que otorgarían a esta norma una estabilidad vital. Se trata de un concepto jurídico, autónomo, que se intersecta constantemente con la Constitución política en dos ámbitos básicos (ámbito social y ámbito axiológico). La interconexión vital de las dos normas justificaría la existencia de un criterio de legitimidad común en las dos Constituciones (el principio de la dignidad humana). Por último, se proponen dos posibles funciones de la Constitución económica, definidas como efectos de la regulación jurídica: la función constitutiva (reconocimiento del mercado como herramienta de

* Este trabajo fue finalizado el 10 abril de 2021. Se inició en el marco de la estancia de investigación en el Max-Planck-Institut für ausländisches öffentliches Recht und Völkerrecht, Heidelberg, Alemania (02.03.2020-01.12.2020). La estancia ha sido parcialmente financiada por el Ministerio de Universidades, España (ayudas de movilidad para estancias breves en otros centros extranjeros a beneficiarios del Subprograma de Formación del Profesorado Universitario, Orden Ministerial de 15 de junio de 2020). Este artículo se ha beneficiado de los comentarios y críticas constructivas de Miguel Azpitarte Sánchez, Kanad Bagchi, Angelo Jr Golia y Michael Ioannidis. Todos los errores restantes son exclusivamente míos. En el trabajo se emplearán estas abreviaturas: a) coord. o coords.: coordinador o coordinadores; b) cfr.: confer («compara»); c) ed. o eds.: edición, editor o editores; d) esp.: especialmente; e) et al.: et alii («y otros»); f) ibid.: ibidem ("en el mismo lugar»); g) núm.: número; h) op. cit.: opus citatum («obra citada»); i) p. o pp.: página o páginas; j) ss.: siguientes; k): trad.: traducción. 
protección de la libertad económica en sentido estricto) y la función potenciadora (garantía de la libertad económica sustantiva y su armonización con el resto de vertientes de la libertad humana).

PALABRAS CLAVE: Constitución económica; ordoliberalismo; legitimidad; dignidad humana.

ABSTRACT: Although it is a commonly used term in contemporary legal doctrine, the concept of "Economic Constitution" allows for widely varying, even conflicting, interpretations. The present contribution aims to outline the essential characteristics of this concept. Following a theoretical overview of the evolution of the Economic Constitution (especially its ordoliberal origins and the most significant alternative definitions at the European level), three basic features are proposed in order to ensure the vital stability of this norm. It is a legal and autonomous concept that consistently overlaps with the Political Constitution on two core areas (social and axiological). The vital interconnection of the two norms could justify the existence of a common criterion of legitimacy within the two Constitutions (the principle of human dignity). Lastly, two possible functions of the Economic Constitution are suggested: foundational (recognition of the market as a tool for the protection of economic freedom in a narrow sense) and enforcement (protection of substantive economic freedom and its harmonization with the other dimensions of human freedom).

KEYWORDS: Economic Constitution; ordoliberalism; legitimacy; human dignity.

SUMARIO: 1. INTRODUCCIÓN.-2. GÉNESIS. LA ESCUELA DE FRIBURGO. 2.1. Primeros intentos conceptuales: Constitución económica como Constitución del trabajo (Arbeitsverfassung). 2.2. La Constitución económica ordoliberal (Wirtschaftsverfassung). 2.2.1. Premisa básica: La democracia tiene efectos nocivos sobre el mercado. 2.2.2 Constitución económica ordoliberal: Definición y características. 2.2.2.1. Fuerza normativa de la Constitución económica: el mercado como medio intrínsecamente democrático y justo. 2.2.2.2. Defensa constitucional del mercado. 2.2.2.3. Constitución económica y Constitución política.-3. HACIA UN CONCEPTO FUNCIONAL CONSTRUIDO SOBRE LA BASE DE LA LIBERTAD. 3.1. Coexistencia de definiciones. 3.1.1. Autonomía conceptual reducida: constitución económica y pluralismo político. 3.1.2. Autonomía conceptual reforzada: la economía social de mercado. 3.2. Rasgos esenciales de un concepto en continua transformación 3.2.1. Un concepto que trasciende el ámbito temporal e ideológico de las definiciones concretas. 3.2.2. Un concepto jurídico. 3.2.3. Constitución política y Constitución económica: ámbitos de intersección. 3.2.4. Un concepto orientado hacia la protección de la libertad humana: funciones de la Constitución económica. 3.2.4.1. Función constitutiva. 3.2.4.2. Función potenciadora.-4. CONCLUSIONES.-5. BIBLIOGRAFÍA

\section{INTRODUCCIÓN}

"Constitución económica" es un concepto ampliamente debatido tanto en la doctrina como en la jurisprudencia constitucional. ${ }^{1}$ No obstante, se observa la existencia de dos problemas fundamentales que subyacen a estos debates y que parecen imposibilitar la construcción de un concepto apto para responder a los retos pre-

\footnotetext{
1 Sobre las distintas posiciones doctrinales existentes, véanse infra notas 3 y ss.
} 
sentes. Por un lado, su origen ordoliberal —elemento incontrovertido- mantiene todavía una influencia considerable, adquiriendo aún mayor intensidad tras la crisis económica surgida en el 2008. Por otro, el espacio normativo nacional (alemán) al que inicialmente se aplicó el concepto (ordoliberal) resulta hoy indiscutiblemente superado por una compleja "constelación constitucional post-unitaria”. ${ }^{2}$

Así pues, algunas de las reflexiones académicas se centran exclusivamente en el contenido contemporáneo de la Constitución económica, con el fin de demostrar —o rechazar - la existencia de influencias ordoliberales y su pertinencia en las circunstancias presentes. ${ }^{3}$ Otras aportaciones doctrinales enfocan las lentes teóricas sobre las presuntas colisiones entre Constituciones económicas en un marco transnacional, abogando por un "constitucionalismo sin Estado" (societal constitutionalism). ${ }^{4}$ Por último, numerosos análisis jurídicos evidencian el impacto de la Constitución económica de la Unión Europea sobre los ordenamientos nacionales, predominando las consideraciones críticas acerca de las transformaciones observadas a raíz de la crisis financiera. ${ }^{5}$

2 Matthias GOLDMANN, "Discretion, Not Rules: Post-Unitary Constitutional Pluralism in the Economic and Monetary Union”, Social Science Research Network, 30.11.2017. Disponible en: https:// ssrn.com/abstract=3103641 (última consulta: 10.04.2021). A pesar de la variedad de metodologías empleadas en la doctrina jurídica, la insuficiencia de una óptica nacional para la resolución de conflictos contemporáneos es un elemento comúnmente aceptado. Por otro lado, el conflicto entre el respecto de las reglas jurídicas y la discrecionalidad económica (modulada por el principio de proporcionalidad) ha quedado plasmado también en el diálogo judicial existente entre el Bundesverfassungsgericht y el Tribunal de Justicia de la Unión Europea: asuntos Gauweiler, de 16 de junio de 2015 (EU:C:2015:400), y Weiss, de 11 de diciembre de 2018 (EU:C:2018:1000).

3 Términos como ordoliberal Europe [Mark BLYTH, Austerity. The history of a dangerous idea, Oxford University Press, Oxford, 2015 (p. 141)] u ordoliberalization of Europe [Thomas BIEBRICHER; Frieder VOGELMANN (eds.), "Introduction", The birth of austerity. German ordoliberalism and contemporary neoliberalism, Rowman Littlefield International, London-New York, 2017 (p. 9)] ponen de manifiesto el objeto de análisis mencionado. En oposición, y defendiendo una progresiva deslegalización de la gobernanza económica tras la crisis (contrario a los postulados ordoliberales), véase Josef HIEN; Christian JOERGES, "Dead man walking? Current European interest in the ordoliberal tradition", European Law Journal, núm. 24, 2018, pp. 142-162 (esp. pp. 155 y ss). En la misma línea, argumentando una actitud basada en el egoísmo nacional y no específicamente en postulados ordoliberales, cfr. Brigitte YOUNG, "Is Germany's and Europe's Crisis Politics Ordoliberal and/or Neoliberal?", en Thomas BIEBRICHER; Frieder VOGELMANN (eds.), op. cit. (esp. pp. 222 y 229). Véase, también, en defensa de un pragmatismo político incongruente con los principios ordoliberales en la gestión de la crisis: Lars P. FELD; Ekkehard A. KÖHLER; Daniel NIENTIEDT, "Ordoliberalism, pragmatism and the eurozone crisis: How the German tradition shaped economic policy in Europe", Freiburger Diskussionspapiere zur Ordungsökonomik, núm. 4, 2015. Disponible en: https://www.econstor. eu/handle/10419/111262 (última consulta: 10.04.2021).

4 Gunther TEUBNER, "Transnational Economic Constitutionalism in the Varieties of Capitalism", The Italian Law Journal, núm. 1, 2015; Idem, Constitutional Fragments. Societal Constitutionalism and Globalization, Oxford University Press, Oxford, 2012. Para un análisis revelador sobre la teoría del constitucionalismo social (en el sentido aquí empleado), cfr. Angelo Jr. GOLIA, "Costituzionalismo sociale (teoria del)", en Rodolfo SACCO (dir.), Raffaele BIFULCO; Alfonso CELOTTO; Marco OLIVETTI (a cura di), Digesto delle Discipline Pubblicistiche, Agg. VII, UTET, Milano, 2017 (esp. pp. 238 y ss.).

5 En este punto, la bibliografía es inabarcable. Cfr., sobre todo: Kaarlo TUORI; Klaus TUORI, The Eurozone Crisis: A Constitutional Analysis, Cambridge University Press, Cambridge, 2013; Michael 
Admitiendo la evidente relevancia de las cuestiones mencionadas, se considera, sin embargo, que los diferentes enfoques ponen de manifiesto una circunstancia que condiciona la propia definición conceptual de la Constitución económica. Concretamente, esta se encuentra en la intersección de diferentes disciplinas científicas (entre las cuales destacan la Economía y el Derecho) y de ordenamientos jurídicos autónomos pero interrelacionados (como mínimo, el nacional y el supranacional). A su vez, la Constitución económica supranacional es el epicentro integrativo de la soñada "unión cada vez más estrecha entre los pueblos europeos". En este contexto, el alcance actual del concepto analizado debería responder simultáneamente a retos de distinta naturaleza; además, sin producir menoscabos irreversibles en la función social de cada uno de los elementos entrecruzados y sin perder ella misma su función integradora.

Como más adelante se verá, la presunta vocación integradora de la Constitución económica apareció ya incorporada en el programa ordoliberal. Pero la misma dependía de la aplicación sistemática del mismo, en cuya base fácilmente se entrevén los ecos ya familiares del "there is no alterative". En pocas palabras, el ordoliberalismo se encuentra en el origen del concepto de Constitución económica; por esta sola razón, debería merecer cierta atención en el estudio jurídico. Si se trata de postulados que han influido en la construcción europea, y hasta qué punto, todavía se debe demostrar. ${ }^{6}$ Pero lo fundamental para este trabajo es determinar qué rasgos del concepto inicial pueden servir para la reconstrucción actual, desde la óptica del constitucionalismo entendido como herramienta de resolución de conflictos (sociales, políticos o económicos ${ }^{7}$ ), con el fin último de garantizar la libertad.

IOANNIDIS, "Europe's New Transformations: How the EU Economic Constitution changed during the eurozone crisis", Common Market Law Review, núm. 53, 2016, pp. 1237-1282; Agustín J. MENÉNDEZ, "La mutación constitucional de la Unión Europea", Revista Española de Derecho Constitucional, núm. 96, septiembre-diciembre 2012, pp. 41-98; Miguel AZPITARTE SÁNCHEZ, "El capitalismo sin mercado financiero y sus consecuencias sobre el Estado constitucional. Crónica política y legislativa del año 2012", Revista Española de Derecho Constitucional, núm. 100, enero-abril, 2014, pp. 151-179; Francisco BALAGUER CALLEJÓN, "Crisis económica y crisis constitucional en Europa”, Revista Española de Derecho Constitucional, núm. 98, mayo-agosto, 2013, pp. 91-107.

${ }_{6}$ Contrario a la opinión general respecto de la influencia ordoliberal en la Constitución económica positiva de la Unión, se ha sostenido que su configuración actual respondería a postulados neoliberales que se enmarcan en el debate internacional de finales de años sesenta entre keynesianimo y monetarismo: Brigitte YOUNG, op. cit.; Lars P. FELD et al., op. cit. En el mismo sentido, cfr. Josef HIEN; Christian JOERGES (eds.), Ordoliberalism, Law and the Rule of Economics, Hart Publishing, Oxford, 2017.

Sobre la vocación aplicativa de la Constitución y la función de resolución de conflictos como condición de su normatividad, véase Miguel AZPITARTE SÁNCHEZ, "Constitución del pluralismo y método jurídico”, Teoría y Realidad Constitucional, núm. 21, 2008, pp. 447-459 (esp. pp. 449-450). Cfr., asimismo, Ignacio GUTIÉRREZ GUTIÉRREZ, "Debates sobre la metodología del Derecho público con la perspectiva de la multiculturalidad y la globalización”, en Miguel Á. PRESNO LINERA (coord.), La metamorfosis del Estado y del Derecho, Fundamentos, núm. 8, Junta General del Principado de Asturias, Oviedo, 2014 (esp. p. 72). Por último, para una propuesta de constitucionalismo social específicamente construida sobre el "Pacto entre Capital y el Trabajo" (dada su "contradicción básica"), cfr. Carlos DE CABO MARTÍN, "El Tratado Constitucional Europeo y el Constitucionalismo del Estado social”, Teoría y realidad constitucional, núm. 19, 2007, pp. 199-213 (esp. p. 201). 
El presente trabajo se compone de dos partes teóricas: en la primera, esencialmente descriptiva, se analizan los orígenes conceptuales de la Constitución económica (2.) y las dos principales interpretaciones existentes a nivel europeo (3.1.). En la segunda parte del trabajo se reflexionará — bajo la fórmula de una contribución prescriptiva conceptual- acerca de las posibles características esenciales de la Constitución económica, desde la perspectiva de la garantía de la libertad; incidiéndose sobre la relación entre la Constitución económica y la Constitución política y sus respectivas esferas de autonomía (3.2).

\section{GÉNESIS. LA ESCUELA DE FRIBURGO}

\subsection{Primeros intentos conceptuales: Constitución económica como Constitución del trabajo (Arbeitsverfassung)}

El término aquí estudiado surgió en la Europa occidental de los inicios de siglo xx; concretamente en 1919, en Weimar. Su mera formulación permite identificar una voluntad de resolución de convulsiones socioeconómicas propias de aquel tiempo. En este sentido, la propuesta intelectual del positivismo jurídico se reducía a un concepto de validez de la Constitución, rechazándose la necesidad de incluir el sistema económico en el programa metodológico de la época. En cambio, en el terreno de las ciencias económicas se negaba cualquier papel del Estado en la organización y funcionamiento del mercado. ${ }^{8}$

Con la Constitución de Weimar, sin embargo, se empieza a construir una vía conceptual novedosa sobre los terrenos movedizos del "problema social", hasta entonces en profunda desconexión con el positivismo jurídico del momento. Desde la perspectiva económica liberal-clásica, se intentaba dar respuesta al conflicto entre el capital y el trabajo ${ }^{9}$, con el propósito último de defender la autonomía del mercado. Desde la óptica jurídica, se iniciaba la búsqueda de fórmulas garantizadoras de la efectividad del Estado frente a los retos de la economía capitalista (especialmente el fenómeno de la técnica) y de resolución de tensiones inherentes entre la libertad y el mercado. ${ }^{10}$ En otras palabras, se sometía a juicio la suficiencia de la igualdad formal para la garantía de la libertad en la democracia capitalista. ${ }^{11}$

8 Knut WOLFANG NÖRR, “"Economic constitution»: On the roots of a legal concept”, Journal of Law and Religion, vol. 11, núm. 1, 1994-1995 (p. 345).

9 Ibid.

10 En particular, sobre la expansión de la técnica como fenómeno incontrolable y su efecto desestabilizador para el Estado, véase Ernst FORSTHOFF, El Estado de la sociedad industrial, trad. J. Nicolás Muñiz y L. López Guerra, CEPC, Madrid, 2013 (esp. pp. 51, 54-55).

11 En cuanto a la oposición inherente entre capitalismo y libertad, véase: Fernando DE LOS RÍOS, El sentido humanista del socialismo, Biblioteca Nueva, Madrid, 2006. Especialmente ilustrativa resulta la caracterización del capitalismo como "Némesis" de "lo humano", "por su indiferencia, cuando no hostilidad" (p. 116). 
En este sentido, las disposiciones contenidas en la Constitución de Weimar son un buen reflejo de los nuevos retos del constitucionalismo de principios de siglo xx. A pesar de su fatídico desenlace histórico en la penumbra nacionalsocialista, la experiencia de Weimar deja constancia escrita de un primer intento conceptual de "Constitución económica". Concretamente, su Capítulo V, dedicado a la "vida económica", señalaba una primera toma de conciencia constitucional acerca del problema social y su relación con el sector económico.

Partiendo del principio genérico de libertad en la vida económica (art. 151), se formulaban limitaciones a la cosmovisión individualista de la sociedad; limitaciones que derivarían de "los principios de justicia, con el objetivo de garantizar a todos la procura de una existencia humanamente digna". ${ }^{12}$ Pero el verdadero germen de la "Constitución económica" aparecía en el art. 165, en el que se anclaba un sistema de Consejos. En concreto, se plasmaba la creación de Consejos de obreros de empresa y económicos de circunscripción, a través de los cuales se perseguía la tutela de intereses colectivos. Lo fundamental de esta construcción era, pues, que, a través de la participación conjunta con los trabajadores, los empresarios dejaban de ser "los dueños exclusivos de la economía". ${ }^{13}$

Este sistema culminaba con un Consejo Supremo de Economía del Reich, estructurado "de manera que [tuvieran] representación en su seno todos los grupos profesionales importantes de acuerdo con su significación económica y social” (art. 165). Con ello, se introducía — al menos teóricamente - un contrapeso político a las decisiones de la mayoría coyuntural, pues el Gobierno del Reich debía someter a informe de este Consejo "todos los proyectos de leyes político-sociales y político-económicas de importancia fundamental, [...] antes de presentarlos" (art. 165). Además, se le reconocía el derecho de iniciativa legislativa y defensa del proyecto ante el Reichtag aun cuando el Gobierno del Reich estuviera en disconformidad.

A pesar de su reducida relevancia práctica y la inferior posición constitucional respecto de otras propuestas planteadas en la asamblea constituyente (reconocimiento del derecho de veto, facultad de convocar referéndum en caso de desacuerdo con el Reichtag, o, incluso, la plena paridad política con el Parlamento) ${ }^{14}$, su mero reconocimiento en la Constitución textual permite encontrar el primer rastro conceptual de "Constitución económica".

La positivización constitucional del sistema de consejos aparecía impregnada de un determinado significado teórico, formulado por el jurista alemán Hugo Sinzheimer en el intento de armonizar la democracia liberal con el socialismo. Bajo esta visión, la economía debía integrar a ambos factores (capital y traba-

12 Ottmar BÜHLER, “Texto de la Constitución alemana de agosto de 1919 y comentario sistemático a sus preceptos" [1929], trad. J. Rovira Armengol, en La Constitución de Weimar, Tecnos, Madrid, 2010 (pp. 313-314).

13 Costantino MORTATI, "Una valoración de conjunto sobre la experiencia de la Constitución de Weimar” [1946], trad. J. L. Aja Sánchez, en La Constitución de Weimar, Tecnos, Madrid, 2010 (p. 61).

14 Ibid. (pp. 37-38) 
jo); una integración que tendría como objetivo último el bien común en materia socioeconómica. ${ }^{15}$

La materialización de esta idea se debía realizar a través del Derecho. Así, empresarios y trabajadores convergerían en un cuerpo común de regulaciones autoimpuestas. De este modo, la clase trabajadora se liberaría de la subordinación al capital, al aparecer igualadas sus posiciones en la toma de decisiones en materia económico-social. ${ }^{16}$ La Constitución económica formulada de este modo cumpliría la función de limitar el poder de los empresarios en la economía capitalista y garantizar la protección de la clase más vulnerable. Se produciría con ello una democratización del sector económico, al estar formado ahora el sujeto decisorio por los dos grupos mencionados. ${ }^{17}$

Resulta llamativo, sobre todo, el lugar que la Constitución económica de Sinzheimer ocupaba en la clásica jerarquía normativa del positivismo jurídico. En concreto, la normatividad de la Arbeitsverfassung descansaba sobre una base autónoma, desvinculada de la Constitución política. ${ }^{18}$ No obstante, su mecánica originaria sería similar al nacimiento de las Constituciones civiles: el sujeto colectivo (en este caso, empresarios y trabajadores) se someten democráticamente al pacto constitutivo, en la búsqueda del bien común en materia económico-social. Por ello, los individuos estarían, a la vez, vinculados por dos Constituciones paralelas y tendrían la simultánea consideración de "ciudadanos económicos" y "ciudadanos del Estado". ${ }^{19}$

La construcción conceptual aquí descrita fue inédita no solo por la introducción de un término novedoso - que, a partir de ese momento sería sometido a debates doctrinales y políticos incesantes hasta hoy-, sino también por su paradójico destino. En efecto, aunque el concepto de Constitución económica apareció con la fallida Constitución de Weimar, desde su propio nacimiento habría tenido la vocación de desvincularse de la Constitución política.

La clave del asunto reside en el hecho de que, una vez desvinculadas desde el punto de vista teórico, la Constitución económica se liberaría también de los problemas de normatividad de la Constitución política, tan vehementemente criticados en la época y que finalmente llevaron a su derrumbe. ${ }^{20} \mathrm{Tal}$ separación podría explicar, entonces, que la posterior gestación ordoliberal del concepto aquí analizado hubiese

15 Hugo SINZHEIMER, Grundzüge des Arbeitsrechts, Fischer Verlag, Jena, 1927 (p. 208).

${ }^{16}$ Ruth DUKES, "A Global Labour Constitution?", Queen's University Belfast School of Law, Enlighten: Publications, 2014 (p. 4). Disponible en: http:/leprints.gla.ac.uk/76158/1/76158.pdf (última consulta: 10.04.2021).

17 Ibid. (p. 1).

18 Gunther TEUBNER, "Transnational Economic Constitutionalism in the Varieties of Capitalism", cit. (p. 6).

19 Ibid. (p. 7).

${ }^{20}$ La recepción del concepto de Constitución económica definido según el impulso socialista quedó ilustrada, por ejemplo, en el art. 1 de la Constitución española de 1931: "España es una República democrática de trabajadores de toda la clase"; en Italia: "L'Italia e una Repubblica [...], fondata sul lavoro" (art. 1. Const. italiana, 1947); y más tarde en las Constituciones soviéticas, por ejemplo, Rumania: "Republica Socialistă România este stat al oamenilor munciï" (art. 1. Const. rumana, 1965). 
encontrado menores obstáculos durante el período nacionalsocialista, hasta el punto de generarse suspicacias sobre la posible cooperación de algunos de los representantes de la Escuela de Friburgo con el régimen totalitario. ${ }^{21}$

\subsection{La Constitución económica ordoliberal (Wirtschaftsverfassung)}

La ciudad de Friburgo fue el terreno que acogió la "combustión intelectual espontánea" 22 de tres científicos identificados con la primera generación ordoliberal: Walter Eucken, Franz Böhm y Großmann-Doerth. La figura central de la Escuela de Friburgo fue Eucken, profesor de Economía política e hijo del reconocido filósofo Rudolf Eucken. En cambio, Böhm y Großmann-Doerth eran ambos juristas, resultando especialmente relevante el trabajo empleado por Böhm en el Ministerio de Economía a partir de 1925 (hasta la llegada del régimen totalitario), tratando de forma específica la problemática de los cárteles económicos.

\subsubsection{Premisa básica: La democracia tiene efectos nocivos sobre el mercado}

Además del documento programático ordoliberal — que más adelante se analizará-, la obra de Walter Eucken resulta reveladora para un primer acercamiento al pensamiento aquí analizado. Más concretamente, se partirá del texto publicado $1932^{23}$ en el que se refleja con claridad una de las premisas básicas de la nueva ideología de germen liberal: la democracia debilitaría la capacidad de funcionamiento y expansión del capitalismo. En este trabajo, Eucken realiza un diagnóstico propio de la crisis del capitalismo evidenciada con la Gran Depresión, desmintiendo la posible pérdida de dinamismo intrínseco del mercado. En cambio, se sostiene que tal crisis se relacionaría con factores externos que alterarían sus bases de funcionamiento eficaz. En particular, a raíz de la apertura moderna del Estado al "poder diabólico

21 Particularmente en relación con W. Eucken. A pesar de su pertenencia documentada a círculos intelectuales contrarios al régimen, en el período nacionalsocialista no emigró y siguió desarrollando su actividad científica especialmente en el marco de la Academia de Derecho Alemán (Akademie für Deutsches Recht) fundada en 1933-1934 y desde la cual se presentaban recomendaciones a los detentadores totalitarios del poder. Cfr. Thomas BIEBRICHER; Frieder VOGELMANN (eds.), op. cit. (p. 42). En sentido contrario, y argumentando la existencia de una "lucha silenciosa" desde Friburgo contra el régimen, cfr. David J. GERBER, "Constitutionalizing the Economy: German Neo-liberalism, Competition Law and the "New Europe»", American Journal of Comparative Law, vol. 42, núm. 25, 1994 (p. 30). Disponible en: https://scholarship.kentlaw.iit.edu/cgi/viewcontent.cgi? article=1220econtext=fac_ schol (última consulta: 10.04.2021). Por otro lado, es preciso destacar aquí la preocupación que subyace en la obra de F. Böhm, acerca de la destrucción de la concentración de poder a través de la libre competencia (entendida como garantía de un espacio de libertad para el individuo): Stefan KOLEV, "Ordoliberalism", en Alain MARCIANO; Giovanni B. RAMELLO (eds.), Encyclopedia of Law and Economics, Springer, New York, 2017, https://doi.org/10.1007/978-1-4614-7883-6_618-3 (pp. 138-139).

22 David J. GERBER, op. cit. (p. 29).

23 "Stuctural Transformations of the State and the Crisis of Capitalism", en Thomas BIEBRICHER; Frieder VOGELMANN (eds.), op. cit., trad. K. Tribe (pp. 51-72). 
del pueblo" ${ }^{24}$ se habría producido una transformación del Estado liberal en "Estado económico".

En el texto subyace una actitud nostálgica hacia el Estado liberal de finales de siglo xix, cuya separación de la sociedad civil había creado el espacio adecuado para que el empresario - figura central en la primera ola de expansión del capitalismopudiera realizar sus intereses económicos privados. La democratización del Estado a través de la universalización del sufragio y el nivel de industrialización alcanzado durante la época de Weimar habían significado para Eucken una "decadencia" en la organización del Estado y la sociedad. ${ }^{25}$

El espacio requerido para el desarrollo natural de las relaciones económicas orientadas según el mecanismo del precio habría sido ocupado por un Estado económico que ya no actuaría según "la razón de Estado", sino según los intereses privados que este intentaría complacer para reconstruir su legitimidad. En pocas palabras, con la democracia de masas, el Estado habría perdido su independencia decisional y se encontraría sometido a los requerimientos de los grupos de presión. La crisis del capitalismo se atribuye, por tanto, a la imbricación del Estado con la sociedad o, lo que es lo mismo según Eucken, a la "politización" de la economía. ${ }^{26}$

De ahí que el Estado intervencionista representara no solo un obstáculo para la economía por el ahogamiento de su espacio vital, sino que se traduciría en un sometimiento del mercado a las "fuerzas caóticas de las masas". ${ }^{27} \mathrm{Y}$ eso debido, en primer lugar, a la imposibilidad técnica de una autoridad central de conocer las necesidades y recursos en cada mercado específico; en segundo lugar, al efecto nocivo que esta intervención tendría sobre el mecanismo del precio ${ }^{28}$, formado según la dinámica básica de la competencia.

Pero, sobre todo, se observa en la obra de Eucken una objeción de principio en relación con el Estado intervencionista: según él, la desaparición de la religión como fuerza orientadora del individuo crearía en la sociedad un "vacío insoportable" que se perseguiría suplir a través de la creencia casi mística en un Estado como entidad sobrehumana. ${ }^{29}$ Según el autor, la expansión capitalista solo se podría realizar en ausencia del Estado, y más concretamente, a través de la conformación de relaciones económicas según el principio básico de la competencia.

24 Ibid. (p. 69). Trad. propia.

25 Ibid., (pp. 55-56).

26 Ibid., (pp. 61, 63, 66).

27 Ibid., (p. 63).

28 Semejanza evidente con el pensamiento neoliberal de la Escuela Austriaca: "The main point is [...] that nobody knows except in so far the market tells him", Friedrich A. HAYEK, Law, Legislation and Liberty, vol. II, The Mirage of Social Justice, 1998, Routledge, London (p. 77).

${ }_{29} \mathrm{Ibid}$., p. 58. El rechazo ordoliberal del Estado intervencionista se puede encontrar con mayor evidencia en la exposición de los dos tipos abstractos de sistemas económicos, en: Walter EUCKEN, "The Different Types of Economic System" [1940], en Thomas BIEBRICHER; Frieder VOGELMANN (eds.), op. cit., trad. T.W. Hutchison (pp. 73-80). 
Todo lo anterior se explicaría, en última instancia, a través de la función metajurídica del principio de libre competencia, siendo esta, en realidad, una herramienta para la materialización de la propia libertad del individuo. Como consecuencia de esta idea, la intervención estatal se traduciría evidentemente en una intromisión en la libertad. De un lado, porque se obstaculizaría la libre realización de planes empresariales guiados en función del precio en el mercado ${ }^{30}$; de otro, porque se imposibilitaría la libre toma de decisiones de los trabajadores acerca de la prestación de sus servicios en las empresas más adecuadas, según su nivel de preparación y expectativas. ${ }^{31}$

En pocas palabras, la politización de la economía a raíz de la democratización del Estado y su consiguiente conversión en "Estado económico" suprimiría el espacio vital del mercado (y de sus participantes) para desarrollarse libremente. Es más, en su búsqueda de legitimidad, el Estado mismo se encontraría sometido a intereses privados, que naturalmente deberían materializarse en el mercado, y no en la política. Según Eucken, el Estado debería reconocer dichos peligros y evitar su imbricación directa con el mercado. La única solución viable para la salvación del Estado (y del mercado) sería, entonces, la liberación pública de la fuerza anárquica de las masas en materia económica. ${ }^{32}$

No obstante, el paradigma del laissez faire absoluto también se consideraba incapaz de responder a los nuevos retos del capitalismo avanzado. De este modo, el propio Eucken se plantea la pregunta natural que surge a raíz de esta exposición: ¿Existe una tercera vía? ${ }^{33}$ Se llega, así, al objetivo primordial del ordoliberalismo: la construcción de una nueva alternativa, apta para asegurar el libre desenvolvimiento de la economía, pero aceptándose implícitamente una premisa ya explicada. En particular, el entendimiento del mercado como espacio primordial para la realización de la libertad individual, bajo la liberación de las fuerzas destructivas de la democracia de masas. Esta tercera vía ordoliberal apareció oficialmente reconocida por los propios representantes de Friburgo en el documento titulado "Nuestra Tarea" (Unsere Aufgabe), publicado el 1936 y firmado por Eucken, Böhm y Großmann-Doerth ${ }^{34}$.

\footnotetext{
30 Walter EUCKEN, "What is the Competitive Order", en Thomas BIEBRICHER; Frieder VOGELMANN (eds.), op. cit., trad. M. Everson, pp. 99-107 (p. 103).

31 Walter EUCKEN, "Competition as the Basic Principle of the Economic Constitution" [1942], en Thomas BIEBRICHER; Frieder VOGELMANN (eds.), op. cit., trad. K. Tribe, pp. 81-98 (p. 95).

32 Walter EUCKEN, "Stuctural Transformations of the State...," cit. (pp. 68-69).

33 Walter EUCKEN, "Competition as the Basic Principle...", cit. (p. 88).

${ }^{34}$ En la traducción inglesa se conoce como The Ordo Manifesto of 1936. En adelante, se encontrará referido como "el Manifiesto Ordo", o simplemente "el Manifiesto".
} 


\subsubsection{Constitución económica ordoliberal: Definición y características}

2.2.2.1. Fuerza normativa de la Constitución económica: el mercado como medio intrínsecamente democrático y justo

La Constitución económica ordoliberal se define como "una decisión política general" acerca de "cómo se debe estructurar la vida económica de la nación". ${ }^{35} \mathrm{Se}$ trata de una "decisión jurídicamente vinculante" ${ }^{36}$ que crea un orden económico determinado, yuxtapuesto al orden político existente. Un primer acercamiento a la definición ordoliberal de la Constitución económica pone de relieve la semejanza entre las finalidades de esta con la teoría clásica de la Constitución, en la cual la norma suprema está destinada asimismo a la ordenación y limitación del poder.

Sin embargo, esta vez se trataría de una materia presuntamente separable de los objetivos constitucionales tradicionales. A pesar de esta distinción, la justificación de la Constitución económica como instrumento jurídico de equilibrio contra exacerbadas acumulaciones de capital o poder —en particular, los monopolios o los cárteles económicos desfigurarían la "justa" estructuración del precio en el mercado- no residiría meramente en la lógica propia del mercado. Al contrario; se trataría, según F. Böhm, de una exigencia derivada de la propia idea de libertad política y, como tal, debería enmarcarse en las preocupaciones de todo ciudadano, y no solo en los "círculos de expertos". ${ }^{37}$

Esta idea podría explicar, a la luz de la construcción ordoliberal, la insuficiencia de la Constitución económica ideada por Hugo Sinzheimer. La inserción de los "grupos afectados" (empresarios y trabajadores) como "poder constituyente" en la Constitución económica produciría, en realidad, un mayor perjuicio a la libertad que la propia salvación de la opresión capitalista que se perseguía. La reducción del círculo de decisión parlamentaria a las clases mencionadas evidenciaría una debilidad de la clase política, que además abriría las puertas al temido sometimiento del Estado al interés privado. ${ }^{38}$

La presunta afectación de la libertad política a consecuencia de la concentración del poder económico se sustenta en una argumentación más amplia, que ilustra la cosmovisión ordoliberal. En concreto, el sistema capitalista contendría una "fuerza" intrínseca —el mecanismo de formación del precio- que garantizaría el máximo grado de libertad posible para el ciudadano (sea este empresario, trabajador o consumidor). Por su articulación conforme a los principios de necesidad, justicia y razo-

35 Ibid.

36 Franz BÖHM, "Economic Ordering as a Problem of Economic Policy and a Problem of the Economic Constitution”, trad. M. Everson, en Thomas BIEBRICHER; Frieder VOGELMANN (eds.), op. cit., pp. 115-120 (pp. 115-116).

37 Franz BÖHM, "Decartelisation and De-concentration. A Problem for Specialists or a Fateful Question?”, en Thomas BIEBRICHER; Frieder VOGELMANN (eds.), op.cit., trad. M. Everson, pp. $121-135$ (p. 122).

38 Ibid. (p. 123). 
nabilidad, este mecanismo convertiría al mercado en un espacio "libre de cualquier arbitrariedad”, en el que la posición inicial de sus participantes sería la de ausencia de poder generalizada. ${ }^{39}$

En particular, el sistema de precios articulado según la lógica de la competencia se define en los textos ordoliberales como una carga necesaria para todo participante en el mercado. Sin embargo, sería una carga ausente de coerción, en tanto que empresarios y consumidores aceptan libremente el precio establecido. La clave del asunto reside en que dicha aceptación no se fundamenta en última instancia en consideraciones metajurídicas (como en la Constitución política), sino en razones de utilidad y razonabilidad: las compras y las ventas se realizan a un determinado precio simplemente porque no existe una alternativa económicamente más satisfactoria. Y, en todo caso, en una reductio ad absurdum, cualquier participante en el mercado que debiera decidir por sí solo sobre el precio "justo", se decantaría sobre la ausencia de onerosidad. ${ }^{40}$

La libre formación del precio representaría, pues, "un continuo procedimiento de otorgación de votos", convirtiendo al mercado en la "expresión más perfecta de la democracia de masas". ${ }^{41}$ Su dinámica basada en la competencia garantizaría la confianza y suficiente previsibilidad para que los actores económicos realicen y desarrollen — con menor y mayor éxito- sus planes, reiterando así su aceptación continuada en el tiempo. De este modo, la configuración ordoliberal de la Constitución económica, al ser intrínsecamente democrática, lograría despojar el nuevo orden de las tan debatidas precondiciones de normatividad de la Constitución política —en particular, la existencia de un pueblo como entidad homogénea sobre el que descansa el principio jurídico de soberanía popular - ${ }^{42}$

La ausencia de coerción inherente a la fuerza del mercado extinguiría, así, las necesidades de argumentación referidas a la legitimidad. La Constitución económica se configura, entonces, como un contralímite jurídico permanente a los centros de poder formados artificialmente, esto es, actores que se sustraen intencionadamente a la dinámica natural del mercado. Pero la lógica de tal limitación constitucional reside en una presunción ordoliberal de justicia del mercado, en cuanto espacio vital para el desarrollo libre del individuo, con base en el principio de competencia perfecta. ${ }^{43}$

39 Ibid. (p. 128).

40 Ibid. (p. 127).

41 Ibid. (p 128).

42 Véase, en este punto, especialmente Ernst W. BÖKENFÖRDE, "La democracia como principio constitucional", en Estudios sobre el Estado de Derecho y la Democracia, Trotta, Madrid, 2000.

43 La competencia perfecta es un tipo ideal de mercado en el que todos los actores económicos aceptan los precios como un dato, sin posibilidad de monopolizar algún sector económico. Al existir, sin embargo, tal posibilidad en la realidad, la regulación estatal deberá suplir esta imperfección en cada caso concreto "como si" se tratara de una competencia perfecta. Esta pretensión básica del ordoliberalismo ha sido uno de los puntos esenciales de objeción en el pensamiento crítico de M. Foucault, para el cual el principio de competencia perfecta sería la manifestación por excelencia de una ideología del poder. Michel FOUCAULT, The Birth of Biopolitics, Picador, New York, 2008 (esp. p. 120). 
Lo anterior pone de manifiesto la existencia de un vínculo indirecto entre la ordenación constitucional económica y la libertad individual. A diferencia de la Constitución política, la Constitución ordoliberal crea un orden económico nuevo alrededor de un mercado que por naturaleza se presenta como democrático y justo, y, por ende, externo per se a debates morales aptos de disminuir su legitimidad. ${ }^{44} \mathrm{Al}$ introducir un blindaje jurídico de "justicia” del precio, la Constitución económica nacería con una garantía intrínseca de aceptación por parte de los actores económicos.

\subsubsection{Defensa constitucional del mercado}

La presunción analizada hasta aquí explica también el resto de las características que delimitan el concepto ordoliberal de Constitución económica. Sus finalidades se podrían reformular en términos de defensa constitucional del mecanismo de formación del precio. A diferencia del laissez faire, la autonomía del mercado se protege no a través de una deferencia política hacia sus dinámicas espontáneas, sino por medio de un reconocimiento constitucionalizado de sus virtudes. Como consecuencia, el Estado "enemigo" de la economía se convierte, con el ordoliberalismo, en cooperador necesario. En un primer momento, actúa como sujeto decisorio sobre el cómo de la ordenación económica del país (fase constitutiva); posteriormente, será el garante de la Constitución económica (fase constituida).

La división temporal en dos fases resulta conveniente para el entendimiento de los principios constitutivos del nuevo orden económico y de la Ordnungspolitik. En la primera etapa, se identifica el origen de un criterio de legitimidad al margen de consideraciones morales, basado en el conocimiento técnico y la funcionalidad práctica. ${ }^{45}$ Evidentemente, en la toma de la decisión política acerca del cómo, serían los científicos de la Economía los responsables de informar sobre las alternativas; más concretamente, sobre la necesidad de su descarte (laissez faire; intervencionismo) y la implementación constitucional de instrumentos para luchar contra cualquier amenaza de distorsión del precio: privada (ej., principio de libre competencia) o pública (ej., principio de estabilidad monetaria). En ausencia de tales instrumentos, la economía se encontraría, pues, en un temido estado anárquico.

Es más, partiendo de la presunta debilidad moderna del Estado a causa de su democratización, la Constitución económica sería asimismo un instrumento de salvación pública, extrayéndose de las manos estatales las herramientas de politización de la Economía (ej. estabilidad monetaria garantizada por una autoridad independiente). Por otro lado, queda también excluida una posible protección constitucional de la clase más vulnerable (trabajadores) defendida por los argumentos del Estado intervencionista clásico. Al partir todo actor económico de una posición generalizada de vulnerabilidad —ya que no se puede planear más allá de lo que dicta la información

${ }_{44}$ Franz BÖHM, "Economic Ordering as a Problem of Economic Policy... cit." (p. 118).

45 Ibid. 
ofrecida por el precio, igual para todos—, la presunta desprotección del trabajador sería, en todo caso, el mal menor entre las alternativas existentes. ${ }^{46}$

La fase de instauración de la Constitución económica plantea la pregunta esencial sobre su relación con la Constitución política. A pesar del sustento legitimador primordialmente práctico y técnico de la primera, la intervención estatal en asegurar el mantenimiento del orden económico establecido crea un vínculo directo con la Constitución política. A fin de no poner en peligro la obediencia ciudadana, la Constitución económica encontraría también sus límites en las reglas y principios básicos de convivencia establecidos en la Constitución política. De esta última se pueden extraer las fronteras del orden económico; el orden político indicaría, pues, las orientaciones que no se pueden seguir en el ámbito económico. ${ }^{47}$

Sin embargo, la Constitución (política) sería insuficiente, según la visión ordoliberal, para determinar todos los principios que deben ordenar el ámbito económico. De este modo, aparece un requisito adicional de precisión en el concepto aquí estudiado. Sin la Constitución económica, la norma suprema de ordenación de la comunidad política quedaría incompleta. Pero, sin la concreción mencionada, la Constitución económica sería un concepto vacío.

\subsubsection{Constitución económica y Constitución política}

La relación entre las dos Constituciones se definiría, entonces, a través de una secuencia de decisiones políticas: la primera crea la comunidad política, con su propia lógica (siendo necesario acudir también a consideraciones de naturaleza moral para fundamentar su legitimidad); la segunda crea el sistema económico más favorable a los requisitos de libertad (en este caso, el blindaje del mercado capitalista, con su mecanismo de formación del precio).

La idea central de impedir cualquier opacidad en el mercado (más concretamente, de la información suministrada por el precio) permite el desarrollo teórico de las dos fases de la Constitución económica mencionadas. En la primera etapa aparecerían, entonces, los "principios constitutivos" ${ }^{48}$, esto es, las líneas estructurales que instauran y explican el funcionamiento del orden económico; además, tendrán la función de guiar la actuación estatal en la protección del mercado constitucionalizado. Entre estos principios se encuentran, en orden de importancia: el correcto funcionamiento del sistema del precio; la primacía de la política monetaria (estabilidad monetaria); el libre mercado; la garantía de la propiedad privada; la libertad contractual; la responsabilidad (jurídica de los propios actos) y la continuidad de la política económica (evitar cambios frecuentes en la política económica). ${ }^{49}$

46 Ibid. (p. 131).

47 Por ejemplo, la "autodeterminación" del pueblo en sentido comunista nunca sería compatible con una economía basada en la libre competencia.

48 Walter EUCKEN, "What is the Competitive Order", cit. (pp. 104-106).

49 David J. GERBER, op. cit., pp. 47-48. Lars P. FELD et al.: op. cit (pp. 13-14). 
La segunda fase se refiere al reconocimiento de "principios de regulación" (regulative principles), que tienen la misión de garantizar la aplicación de los principios constitutivos. ${ }^{50}$ En realidad, la segunda etapa se refiere al cumplimiento eficaz de la norma orientadora de la economía y proyecta como actor esencial al Estado, a través del Ordnungspolitik ("la política del orden"). Esta última se implementa mediante la regulación de soluciones concretas y es necesaria para asegurar la coherencia sistemática de la actividad económica a lo largo del tiempo.

En este sentido, la Constitución monetaria ordoliberal se construye como otro pilar sustentador del sistema ordoliberal en su conjunto. Al existir una interdependencia entre todos los elementos que influyen en la implementación de la decisión política en materia económica, el valor de la moneda (como unidad de intercambio en el mercado libre) también tendría el potencial de afectar, primero, al cálculo individual de los planes económicos y, después, como parte del sistema, a la coordinación en sentido amplio de la economía. ${ }^{51}$

Se observa, por tanto, que la primacía de la estabilidad de precios y la sustracción de su aseguramiento de las manos políticas son principios ordoliberales que persiguen primordialmente la construcción de una base económico-constitucional de defensa de la información suministrada por el precio. La estabilidad de la moneda se configura, en definitiva, como "una precondición vital" para el funcionamiento adecuado del orden competitivo, y se define, según los representantes de Friburgo, en términos de ausencia de inflación o deflación significativas. ${ }^{52}$

Todo lo anterior demuestra que el concepto ordoliberal de Constitución económica introduce, en realidad, un programa constitucional basado en la presunción de justicia, necesidad y razonabilidad del precio en un mercado libre. Su protección justifica la existencia de los principios constitucionales estudiados y la proyección de un Estado "fuerte", liberado de las fuerzas anárquicas del pluralismo político. Su papel de garante del orden económico a través del Ordnungspolitik le salva de su antigua posición de "enemigo" de la economía, pues su actuación no puede ir más allá de lo constitucionalmente permitido. Tal salvación se extiende en el tiempo debido a la vocación de permanencia de la Constitución económica; de manera que este concepto no representa solo una garantía de la economía capitalista, sino también, un instrumento de prevención para futuras "amenazas" de la misma (ej. expectativas ciudadanas de un Estado prestacional).

50 Entre estos principios se encuentran, por ejemplo, el principio de libre competencia, la prohibición de la competencia desleal...

51 Walter EUCKEN, "The Different Types of Economic System”, cit., (p. 79).

52 Walter EUCKEN, "Competition as the Basic Principle...", cit. (p. 94). No obstante, la positivización del principio de estabilidad monetaria en el orden jurídico alemán no se produjo hasta el 1957, con el Bundesbankgesetz (BBankG), de 26 de julio (art. 3); siendo posteriormente elevado a rango constitucional (art. 88 de la Ley Fundamental) a raíz de las disposiciones acordadas en el Tratado de Maastricht de 1993 (estabilidad monetaria como objetivo primordial de los bancos centrales nacionales, art. 105; caracterizados por su independencia técnica, art. 107). 
A pesar de insertar un paralelismo teórico en cuanto a los criterios de legitimidad de las Constituciones económica y política, la interdependencia de las dos decisiones políticas es evidente. En particular, la específica posición ordoliberal del Estado en la economía impide el desarrollo de políticas sociales, imposibilitando a largo plazo una respuesta constitucional distinta al conflicto capital-trabajo, más allá de asumir la vulnerabilidad del trabajador como "un mal menor". En realidad, la positivización de los principios ordoliberales implica para la comunidad política de referencia la aceptación de la igualdad formal como elemento característico, pues las medidas prestacionales requeridas por la igualdad en sentido material entrarían en conflicto con las premisas de la Constitución económica.

Se puede percibir, entonces, que las expectativas ciudadanas de libertad aparecen condicionadas por la necesidad teórica de mantener la correcta formación del mecanismo del precio. Y, en todo caso, según la óptica ordoliberal, habían sido estas propias exigencias de igualdad material las que llevaron a la transformación del "Estado económico" y, con ello, a la destrucción de las condiciones de funcionamiento del mercado.

Es cierto que la diferenciación entre los criterios de legitimidad y la existencia de dos órdenes (económico y político) logra salvar al mercado de los problemas de normatividad de la Constitución política. Sin embargo, se crea un problema adicional para esta última, al quedar vedada cualquier actuación pública que busque asegurar la libertad en su vertiente material. Con ello, se produce un traspaso tácito de la cosmovisión ordoliberal al ámbito político, en relación con la presunción de justicia, necesidad y razonabilidad del mercado. A pesar de la fundamentación primordial de esta premisa en el argumento de ausencia de consideraciones morales, la realización del principio constitucional del Estado social (que sí requiere algunas reflexiones relativas a la justicia redistributiva) queda permanentemente imposibilitada. En definitiva, la definición ordoliberal de la Constitución económica depende de la existencia de una comunidad política autodefinida según la cosmovisión ordoliberal.

Aparece, en este punto, la consecuencia de una ciencia transformadora de la sociedad, defendida por los representantes de Friburgo. Con ello, la Constitución económica de la época de Weimar - que perseguía la organización del mercado según "los principios de justicia" ${ }^{3}$ — queda reducida a la idea de justicia en el mercado. La garantía de una "existencia humanamente digna" se materializa, con el ordoliberalismo, en el mero reconocimiento constitucional del mercado como medio idóneo para su búsqueda.

En este sentido, la responsabilidad del Estado para procurar tal vida digna se limita también al Ordnungspolitik, produciéndose una liberación en dos sentidos. De un lado, el Estado queda desvinculado de la economía y, en realidad, de sus obligaciones positivas de redistribución social. De otro, el ciudadano tiene constitucionalmente

53 "[c]on el objetivo de garantizar a todos la procura de una existencia humanamente digna" (art. 151 de la Constitución de Weimar). 
asegurado un espacio idóneo para desenvolverse según sus planes individuales, que se podrán llevar a cabo sin la invasión del Estado y sin falseamientos de la información necesaria a raíz de concentraciones de poder privado.

No obstante, tal liberación presenta una manifestación adicional, referida a la responsabilidad individual en la consecución de una existencia humanamente digna. Con ello, se pone de manifiesto una vez más la extensión de los principios ordoliberales de la Constitución económica a las bases de ordenación política de la comunidad. La idea de responsabilidad individual no es meramente una consecuencia lógica del programa ordoliberal, sino que se trata de una obligación básica de los participantes en el mercado: la minimización de la responsabilidad personal transformaría fundamentalmente la evaluación de los costes y riesgos, con lo cual se disminuiría la diligencia necesaria en la planificación individual ${ }^{54}$. El resultado de lo anterior sería la vulneración del propio motor del capitalismo: un mercado basado justamente en la capacidad innovadora y planificadora de sus agentes.

La imposición de la responsabilidad individual en la gestión de los planes empresariales se encuentra, pues, en máxima coherencia con un mercado altamente competitivo y la abstención estatal. Se pone de manifiesto que una de las ideas de base en la construcción ordoliberal consiste en la prevalencia de la lógica de la competencia (y no del gasto) como clave de la prosperidad económica. En particular, la lucha contra las concentraciones de poder privado y la atribución de la garantía de la estabilidad de precios a una autoridad independiente consolidarían el marco de actuación idóneo para que las empresas centraran los esfuerzos en la mejora de sus productos. Así, el fomento constitucional de una dinámica altamente competitiva produciría, a largo plazo, un aumento en la calidad de los productos nacionales y, con ello, una alta demanda a nivel internacional. ${ }^{55}$

Uniendo esta idea a la obligación de responsabilidad individual ya explicada, se observa que la Constitución económica ordoliberal abre la puerta intelectual al posible reproche de culpabilidad resultada de una supuesta falta de diligencia; dado que los esfuerzos personales deben dirigirse a la mejora de los productos y, en definitiva, a mejorar la propia posición en el mercado, creando finalmente una oferta nacional altamente demandada y aumentando el nivel de prosperidad económica del país. Se explica, con ello, la necesidad de aplicar los principios ordoliberales de manera sistemática, pues el fallo de cualquiera de sus partes llevaría al derrumbe del edificio teórico. En adición, la íntima vinculación entre las Constituciones política y económica transforma al mercado en un factor de integración de la sociedad civil, buscándose suplir con su lógica presuntamente justa la ausencia de un Estado social.

Así, en vez de pagar el precio de un Estado débil guiado por intereses privados, la Constitución política solamente tendría que crear el espacio normativo para la Constitución económica, nutriéndose posteriormente de sus efectos benéficos sobre

\footnotetext{
54 Lars P. FELD et al., op. cit. (p. 14).

55 Mark BLYTH, Austerity... cit. (p. 137).
} 
la sociedad. En particular porque, al introducirse la obligación implícita de responsabilidad individual a través de la lógica altamente competitiva ya presentada, se salvan también los posibles problemas de normatividad de la Constitución política ligados al Estado social: será el reproche personal, y no la intervención estatal, la respuesta hacia las desigualdades derivadas del mercado capitalista. Al instalarse con el concepto ordoliberal la expectativa de "diligencia personal", tales desigualdades serían en todo caso consecuencias de la falta de esta diligencia, pues los fallos del mercado ya habían recibido una respuesta constitucional. Por ende, su gestión también debería corresponder al responsable del error, desapareciendo así la creencia en un Estado "místico" salvador.

\section{HACIA UN CONCEPTO FUNCIONAL CONSTRUIDO SOBRE LA BASE DE LA LIBERTAD}

\subsection{Coexistencia de definiciones}

Hasta aquí se ha visto que el concepto de Constitución económica ha ido adquiriendo, desde sus orígenes, distintos rasgos, que en ciertos extremos han resultado hasta opuestos. Mientras que en la definición ordoliberal, este concepto aparecía como una herramienta de garantía perpetua de un mercado por naturaleza democrático, la Constitución económica de Hugo Sinzheimer se construía justamente sobre la necesidad de democratización del mercado a través de la integración del factor trabajo en la toma de decisiones. A pesar de las distintas características, se observa un denominador común referido a las funciones básicas de la Constitución económica, propias del constitucionalismo: la ordenación y limitación del poder.

Las diferentes ópticas sacan a luz la necesidad de reflexionar sobre las premisas desde las cuales el concepto estudiado se dota de contenido, y también sobre el objetivo perseguido por este. Pues, como se ha visto, una misma función (ej., limitación del poder) puede encontrarse positivizada de distintas maneras, en relación con el bien jurídico que se busca proteger. En el caso ordoliberal, el propio mercado es objeto de protección constitucional, derivándose la necesidad de limitar tanto el poder privado como el público, proyectando esto las consecuencias ya analizadas sobre el principio constitucional del Estado social. En cambio, las disposiciones de la Constitución de Weimar referidas al sistema económico buscaban garantizar la igualdad material, reconociendo la voz decisoria de los trabajadores junto a los empresarios y orientando la garantía de la propiedad privada a una función social.

Las consideraciones realizadas en relación con la génesis del concepto de Constitución económica ponen de manifiesto la complejidad originaria del mismo y su heterogénea concreción en el Derecho positivo. No obstante, su posterior desarrollo diversifica aún más las posibilidades interpretativas de este concepto. En el siguiente epígrafe se presentarán algunas de las más importantes concreciones teóricas, incidiendo sobre sus virtudes e insuficiencias a la luz del constitucionalismo. 


\subsubsection{Autonomía conceptual reducida: Constitución económica y pluralismo político}

Existe un acuerdo generalizado en la doctrina jurídica y la jurisprudencia constitucional sobre la posibilidad de definir el concepto aquí analizado en un sentido meramente descriptivo o formal. Así, la Constitución económica se definiría como la totalidad de disposiciones jurídicas destinadas a regular el comportamiento económico en un determinado ámbito territorial. ${ }^{56}$ Sin embargo, una observación más atenta permite desvelar la mera superficialidad de la definición mencionada, pues el carácter presuntamente descriptivo conlleva también la aceptación de ciertas premisas implícitas. La primera de ellas se refiere a la pertinencia de la intervención —sea esta mínima - del Estado en la economía; la segunda, a la función limitadora de la Constitución económica y su eficacia sobre ámbitos territoriales concretos. ${ }^{57}$

A pesar de que el empleo en sentido formal de la definición se realiza en la doctrina jurídica con el objetivo de sacar a luz su insuficiencia - y la correspondiente necesidad de dotarla de componentes ideológicos-, la presunta vaciedad del concepto no resulta en absoluto evidente. En realidad, la consecuencia automática de una definición en sentido formal no es la imposibilidad, sino simplemente la dificultad considerable para extraer su contenido. Una dificultad que se podría traducir en la existencia de un principio de neutralidad ideológica en la Constitución económica, i.e. una deferencia constitucionalizada hacia el legislador democrático en la organización de la economía. ${ }^{58}$

Es evidente que esta interpretación requeriría, entonces, el alejamiento teórico de las premisas ordoliberales ya estudiadas. En particular porque - como se ha explicado - una apertura de la Constitución económica hacia la democracia significaría, desde la perspectiva ordoliberal, una apertura al peligro de las masas; observándose de este modo una tendencia de la Constitución económica intrínseca al caos. Por ende, si se acepta en abstracto la procedencia de un principio de neutralidad ideológica, el concepto aquí estudiado deberá desprenderse de sus raíces ordoliberales en lo que a su esencia antidemocrática se refiere.

56 Cfr., sobre todo, Armin HATJE, "The Economic Constitution within the Internal Market", en Armin VON BOGDANDY; Jürgen BAST (eds.), Principles of European Constitutional Law, Hart, Oregon, 2010 (p. 591). Tony PROSSER, The Economic Constitution, Oxford University Press, New York, 2014 (pp. 7-8); Manfred E. STREIT; Werner MUSSLER, "The Economic Constitution of the European Community: From ‘Rome' to 'Maastricht'”, European Law Journal, vol. 1, núm. 1, marzo 1995, pp. 5-30.

57 No obstante, téngase presente la oposición estructural a las premisas mencionadas de la teoría del constitucionalismo social. Cfr., Gunther TEUBNER, Constitutional Fragments... cit. (esp. pp. 5-14, 43).

$58 \mathrm{Al}$ menos hasta la reforma constitucional del art. 135 [BOE, núm. 233, de 27 de septiembre de 2011, pp. 101931 a 101941; BOE-A-2011-15210], esta ha sido la interpretación sostenida por Tribunal Constitucional español. En realidad, la mención explícita del término "Constitución económica" se ha empleado por primera vez en la jurisprudencia española en el Voto Particular formulado por el Magistrado don Luis Díez-Picazo, a la STC 37/1981, de 16 de noviembre (BOE, núm. 285, de 28 de noviembre de 1981), en el que se introduce con claridad el principio fundamental de neutralidad ideológica. 
Admitiendo, pues, la interpretación propuesta, se plantearían a continuación dos interrogantes: ¿qué utilidad tiene una Constitución económica que no aclara sobre los objetivos deseados en el sistema económico? ${ }^{59}$; y ¿qué argumentos de teoría constitucional podrían justificar tal neutralidad ideológica? Existen como mínimo dos razones que evidencian la utilidad de una Constitución económica ideológicamente neutral.

En primer lugar, la mera regulación de los elementos estructurales de la economía a nivel constitucional pone de manifiesto la existencia de un interés público hacia las dinámicas del mercado. En este sentido, la Constitución económica — sea esta formal - se diferencia desde su propia base teórica del laissez faire absoluto, para el cual el máximo nivel de intervención estatal aceptable se refiere a la garantía de la propiedad privada. ${ }^{60}$ En otras palabras, la identificación del mercado como objeto de interés constitucional manifiesta el reconocimiento de una posible tensión inherente entre la libertad individual y los elementos estructurales de la economía. Se identifica en la norma constitucional una función potencialmente correctora del poder público sobre los desequilibrios observados en el mercado; la decisión sobre cómo atenuar esta tensión le corresponderá, sin embargo, al legislador democrático.

Es cierto que podría decidirse una intervención mínima, coincidente con los postulados del laissez faire. La diferencia consiste en que, al reconocerse la existencia de un interés constitucional en la regulación de la economía, se impone también al legislador un deber de actuación en el sentido más oportuno para la garantía de la libertad, y no una obligación de abstención ligada a los requisitos de libertad en sen-

59 En cuanto al debate doctrinal en Espańa, en el contexto inmediatamente posterior a la Transición: defendiéndose la variedad de modelos económicos posibles dentro del marco general diseñado en la Constitución española cfr. Manuel GARCÍA PELAYO, "Consideraciones sobre las cláusulas económicas de la Constitución”, en Manuel RAMÍREZ JIMÉNEZ (ed.), Estudios sobre la Constitución española de 1978, Libros Pórtico, Zaragoza, 1979 (p. 46). Acerca de la relación de la Constitución económica española con los principios rectores del Estado social, Aurelio MENÉNDEZ MENÉNDEZ, "Constitución, sistema económico y Derecho mercantil", Hacienda Pública Española, núm. 94, 1985. Definiendo la Constitución económica como el conjunto de principios ordenadores de la actividad económica de los poderes públicos y agentes privados, Sebastián MARTÍN-RETORTILLO, Derecho Administrativo Económico, tomo I, La Ley, Madrid, 1991. Más recientemente, sobre la ausencia de un modelo económico constitucional, conllevando a una definición de Constitución económica "formal y abierta": Enoch ALBERTÍ ROVIRA, "La Constitución Económica de 1978. Reflexiones sobre la proyección de la Constitución sobre la economía en el XXV Aniversario de la Constitución española", Revista Española de Derecho Constitucional, año 24, núm. 71, mayo-agosto, 2004, pp. 123-159 (p. 125). Véanse, también, acerca del concepto aquí estudiado: Luis I. GORDILLO PÉREZ, "Constitución económica, ordoliberalismo y Unión Europea. De un derecho económico nacional a uno europeo", Revista de Derecho UNED, núm. 23, 2018, pp. 249-283; Gabriel MORENO GONZÁLEZ, "Más allá de la Regla de Oro: las otras restricciones constitucionales al poder fiscal y presupuestario", Revista Española de Derecho Constitucional, núm. 115, 2019, pp. 205-227.

60 "The minimal state is the most extensive state that can be justified. Any state more extensive violates people's rights", Robert NOZICK, Anarchy, State, and Utopia, Blackwell, Oxford UK \& Cambridge USA, 1999, p. 149. Siguiendo, en este sentido, la línea del liberalismo clásico para el cual la propia fundación teórica del Estado giraba en torno a la garantía de los derechos de contenido económico. John LOCKE, Second Treatise of Government, cap. IX, en Richard H. COX (ed.), E-book, Wiley-Blackwell (para.123-124). 
tido negativo. ${ }^{61}$ Es más, la decisión sobre una intervención mínima sería, esta vez, sometida a la fiscalización de los ciudadanos, a los efectos de la responsabilidad política.

En segundo lugar, la ausencia de precisión acerca de los objetivos de la economía nacional obliga a volver la mirada sobre la relación entre la Constitución económica y la Constitución política, pues según su configuración inicial (ordoliberal), sería esta última la que articularía los límites de la actuación democrática en materia económica. La relevancia de esta idea se pone de manifiesto especialmente en el contexto actual, dominado por un poder económico globalizado frente al cual el Estado se ve incapaz de dar respuestas satisfactorias y en cual la normatividad de la Constitución política depende específicamente de la eficacia de tales respuestas. La posibilidad de una Constitución económica en sentido ideológicamente neutral ayuda a reflexionar con más intensidad sobre los límites genéricos de actuación que se imponen al legislador; destacando, entre ellos, la protección efectiva de los derechos fundamentales. ${ }^{62}$

Pero, además, al ser los derechos fundamentales una frontera genérica de prohibido traspaso para el legislador, se abre una vía teórica adicional que ayuda a reflexionar nuevamente sobre los criterios primordiales de legitimidad del poder político. En efecto, se observa la posibilidad de que la democracia no sea el único —o el últimofundamento de normatividad de la Constitución política. Esta idea resulta esencial para entender también la relación conceptual entre la Constitución económica y la Constitución política; la coherencia estructural del análisis aconseja, sin embargo, volver sobre esta reflexión más adelante.

Más allá de los argumentos referidos a la posible utilidad de una definición formal, existe una razón adicional apta para combatir la presunta vaciedad del concepto aquí estudiado. En particular, el principio de neutralidad ideológica se podría conformar como un punto de armonización entre la Constitución política y la Constitución económica, a la luz del principio democrático.

Esta idea requiere partir del significado constitucional de la democracia como método de canalización y resolución de conflictos basado en el pluralismo político y la posibilidad de alternancia. ${ }^{63}$ En este sentido, resulta de especial relevancia para este trabajo la manifestación de la alternancia como "oferta plural" de soluciones recaídas sobre un mismo conflicto, con la finalidad de dotar de significado real el

${ }^{61}$ Según la clásica distinción realizada por Isaiah BERLIN, “Two concepts of liberty”, en Henry HARDY (ed.), Liberty, Oxford University Press, New York, 2002 (pp. 169-170).

${ }_{62}$ En este mismo sentido se ha pronunciado el Tribunal Federal Constitucional Alemán en la BVer$f G E$ 50, 290 (asunto Mitbestimmung), de 1979, al reconocer el principio de neutralidad ideológica en la Constitución económica alemana (esp. para. 140). Más concretamente, "se trata de unir la libertad fundamental de configuración de la política económica y social, que debe preservarse para el legislador, con la protección de la libertad, a la que el ciudadano individual tiene un derecho constitucional, en particular frente al legislador" (para. 142, trad. propia).

${ }^{63}$ Miguel AZPITARTE SÁNCHEZ, "Alternancia y reconstrucción de la Constitución económica. Crónica política y legislativa del año 2011”, Revista Española de Derecho Constitucional, núm. 94, eneroabril, 2012, pp. 183-208. 
voto del elector, decidido sobre una base amplia de posibilidades. ${ }^{64}$ Así interpretada, la incorporación del principio de neutralidad política en la Constitución económica se traduciría en el sometimiento de esta última a la dinámica decisoria clásica, diferenciándose conceptualmente de la Constitución política simplemente en razón de su especificidad material (política socioeconómica).

Con ello, se produciría asimismo una transformación del criterio de legitimidad propio de la Constitución económica (la justicia inherente a la lógica económica), en tanto que el objeto de su regulación —el mercado- se encontraría ahora sometido a la modulación de las fuerzas políticas democráticamente designadas. En definitiva, a los efectos de su normatividad, el concepto aquí analizado tomaría un punto de referencia común con la Constitución política: el proceso electoral.

Todo lo anterior demuestra que, a pesar de su origen ordoliberal, una definición formal de la Constitución económica no sería, de entrada, insuficiente. En el presente epígrafe se ha propuesto su interpretación en el sentido de una deferencia constitucionalizada hacia el legislador democrático. Pero ¿qué valor ańadido suministra tal interpretación al debate actual referido a la Constitución económica?

En primer lugar, se observa que, en realidad, no existe un requisito inherente de precisión en el concepto de "Constitución económica". La tarea de encontrar razones adicionales a la luz del constitucionalismo para fundamentar la presunta insuficiencia de una definición formal se encuentra todavía pendiente. En segundo lugar, la posibilidad de interpretar la Constitución económica en sentido meramente formal advierte sobre su carácter abierto en el tiempo, aumentándose de forma considerable "lo [constitucionalmente] posible" según las preferencias de la mayoría coyuntural. Sin embargo, "lo posible" deberá someterse a los límites diseñados por "lo necesario", destacando en este punto la protección de la libertad individual (la garantía de los derechos fundamentales). ${ }^{65}$

Por último, la presunta existencia de un criterio legitimador específico en la Constitución económica —eficacia y conocimiento técnico, según los postulados de la Escuela de Friburgo - plantea la necesidad de reflexionar sobre la propia función legitimadora de la democracia y, más concretamente, sobre los argumentos que recomiendan o desaconsejan integrarla con carácter exclusivo en la teoría de la Constitución económica. En definitiva, hasta aquí se ha visto que el concepto de Constitución económica permitiría tanto la defensa de la neutralidad ideológica como la limitación sustancial del poder legislativo en materia económica. Si en sus orígenes, tal limitación se argumentaba en relación con el miedo al "poder diabólico de las masas", en la Constitución económica de posguerra se instala la presunción de legitimidad exclusivamente democrática del poder.

64 Ibid. (pp. 190-191).

65 Sobre la democracia como "principio constitucional legitimador específico y abierto hacia el futuro" y la integración de "lo posible" y "lo necesario" (normativo) en la Constitución, cfr. Peter HÄBERLE, Tiempo y Constitución, trad. J. L. León Vásquez, Palestra Editores, Lima, 2017 (particularmente pp. 29-32). 
A pesar de la discrepancia extrema entre las dos versiones, se puede observar la existencia de un elemento común en el discurso teórico: la paradoja de proteger la libertad (los derechos fundamentales en sentido amplio), sin vulnerar la libertad (derechos y libertades económicas). ${ }^{66} \mathrm{La}$ interpretación de esta paradoja bajo la óptica del constitucionalismo indicaría la posibilidad teórica de imponer límites a la mayoría democráticamente legitimada, siempre que esta limitación produzca un aumento considerable del nivel de libertad (política y económica) de los ciudadanos, y sin que ello suponga un perjuicio desproporcionado para la democracia.

\subsubsection{Autonomía conceptual reforzada: la economía social de mercado}

A raíz del epígrafe anterior se extrae la idea de que toda definición en sentido sustantivo de la Constitución económica implicaría una modulación restrictiva del principio de neutralidad ideológica y, por ende, una limitación de la actuación del legislador democrático. Pero, como ya se ha visto, estas limitaciones no se deben interpretar, sin al menos una reflexión crítica, como antidemocráticas. Pues limitar al legislador no significa poner cuestión la trascendencia constitucional de la democracia; al contrario, se puede defender la idea de que ciertas limitaciones - constitucionalmente justificadas - a la mayoría coyuntural potencian la propia democracia.

Realizar un análisis exhaustivo de las definiciones existentes en la literatura jurídica sería una tarea que supera el propósito de este trabajo. Sin embargo, cabe incidir sobre una de las concretizaciones más significativas del concepto aquí analizado, debido a su impacto actual en la interpretación de la Constitución económica supranacional. Se trata, en particular, de la definición de la Constitución económica en el sentido de una economía social de mercado (die Soziale Marktwirtschaft), propuesta por una nueva generación de ordoliberales en el contexto alemán de posguerra. ${ }^{67}$

En este contexto histórico — definido por una profunda inestabilidad política y económica ${ }^{68}$ - la intervención de una "ciencia fuerte" capaz de ofrecer soluciones rápidas resultaba especialmente oportuna. A diferencia de lo ocurrido en la época de Weimar, la urgencia de eliminar la pobreza extrema y la necesidad de reconstrucción económica y política abrieron las puertas a la aceptación de una "tercera vía" que había nacido — ya antes de la Segunda Guerra Mundial— específicamente con

${ }^{66}$ Sobre el dilema liberal Can't live with it, can 't live without it (referido a la relación entre la Economía y el poder público), véase Mark BLYTH, op. cit. (pp. 106-115).

${ }_{67}$ La referencia a una "segunda generación" se realiza solamente a efectos de simplificación y énfasis en la nueva orientación social de la Constitución económica. Figuras representantes: Alfred MüllerArmack, Wilhelm Röpke y Alexander Rüstow. Especialmente relevante para el estudio de la economía social de mercado resulta Müller-Armack, siendo este el propio impulsor del término.

68 "Todos y todo, con la notable excepción de las bien alimentadas fuerzas de ocupación aliadas, parecen acabados, sin recursos, exhaustos", Tony JUDT, Postguerra. Una historia de Europa desde 1945, trad. J. Cuellár y V. E. Gordo del Rey, Taurus, Madrid, 2005 (p. 35). 
la misión de reconstruir, sobre la base del caos. Y es que, esta vez, el orden político estaba dispuesto a integrar los postulados de la Constitución económica ordoliberal, pues la nueva legitimidad del orden político aparecía desde orígenes minada; entre otros aspectos, debido a la imposición externa (por parte de los poderes Aliados) de sus fundamentos básicos.

Sin enumerar las complejas circunstancias políticas, sociales y económicas de la Alemania Occidental de posguerra, es evidente que la consecución de un rápido crecimiento económico se configuraba como elemento determinante para legitimar el poder político. En este sentido, la propuesta ordoliberal ya estudiada parecía ofrecer la receta del éxito; la notoria reforma monetaria de Ludwig Edhard ${ }^{69}$ y la restauración de los principios de economía de mercado supusieron, a largo plazo, un triunfo político del Erst Sparen, Dann Kaufen! ${ }^{70}$ Sin embargo, dada la precariedad de las condiciones económicas y sociales y la importancia crítica del momento histórico, la reconstrucción económica debía integrar, esta vez, una promesa específica de estabilización sociopolítica.

La Constitución económica definida como economía social de mercado implicaría, entonces, la instauración de los principios ordoliberales ya estudiados, integrando además un nuevo objetivo referido al "progreso social" ${ }^{71}$. La diferencia con un Estado intervencionista clásico se observaría — según los autores ordoliberales- no en los objetivos (pues el sistema económico se orientaría ahora hacia la consecución de "fines de interés social") sino en los instrumentos empleados. La clave consiste en que serán los principios de la Constitución económica - y no los de la Constitución política - los que determinarán la validez de estos instrumentos. Más concretamente, se trataría del criterio del marktkonform (conformidad con el mercado). De este modo, la consecución de los fines sociales será posible siempre que el normal funcionamiento del mercado quede preservado; pues en caso contrario se vulneraría de forma directa la libertad individual definida (desde la óptica ordoliberal) como la igual oportunidad de realización de planes individuales de acuerdo con el principio básico de la competencia. ${ }^{72}$

69 Edhard había escrito su tesis doctoral bajo la supervisión del economista Franz Oppenheimer, creador de la expresión clave de la ideología ordoliberal, "La Tercera Vía” (Der dritte Weg, 1933). Thomas BIEBRICHER; Frieder VOGELMANN (eds.), op. cit. (p. 137). Durante el período de reconstrucción, W. Eucken y F. Böhm, entre otros, fueron miembros del Consejo Asesor de su Ministerio. Además, en 1952, Edhard nombró a Alfred Müller-Armack como director del departamento central de política económica de este mismo Ministerio.

70 "Ahorrar primero, consumir después". Para una explicación detallada del Erst Sparen, Dann Kaufen y su paralelismo con las ideas keynesianas, cfr. Mark BLYTH, op. cit. (esp. pp. 38-43). En cuanto a la importancia del perfil histórico exportador de Alemania para la consecución del "milagro económico alemán”, cfr., ibid. (pp. 133-138).

71 Alfred MÜLLER-ARMACK, "The meaning of the social market economy", en Alan T. PEACOCK; Hans WILLGERODT (eds.), Germany's Social Market Economy: Origins and Evolution, Palgrave Macmillan, New York, 1989 (pp. 82-83).

72 Alexander von RÜSTOW, "General Sociological Causes of the Economic Disintegration and Possibilities of Reconstruction”, en Thomas BIEBRICHER; Frieder VOGELMANN (eds.), op. cit., trad. D. Steuer (p. 152). 
De este modo, a la vez que integra un componente social, la nueva definición de la Constitución económica introduce un condicionante para la libertad en sentido material: las políticas sociales se deberán someter al juicio de compatibilidad con el mercado. Igual que el principio de neutralidad ideológica, la economía social de mercado requeriría la ponderación casuística de la actividad del legislador democrático. Sin embargo, la modulación de su margen de actuación se realizará no en función de los contenidos esenciales de los derechos fundamentales, sino en función de las reglas básicas del mercado. ${ }^{73}$

En pocas palabras, la definición de la Constitución económica en el sentido de una economía social de mercado, especialmente influida por su contexto de origen, implica un giro teórico en la relación Estado-sociedad, mediada por las virtudes del mercado fundamentado en la dinámica básica de la competencia. En un primer momento, se produciría la propia atribución de legitimidad al poder político, a través de la eliminación de las condiciones de pobreza extrema; posteriormente, el Estado se limitaría a la protección de esta dinámica económica, interviniendo en la sociedad tan solo para reasegurar su legitimidad en momentos puntuales, pero sin perturbar la promesa de crecimiento económico del país.

Se trata, en definitiva, de una Constitución económica que vuelve a tener al mercado como objeto primordial de protección, pero "destapando", esta vez, sus ojos hacia los problemas de la sociedad, permitiendo de esta forma la realización puntual de políticas destinadas a mejorar las condiciones de vida de los ciudadanos. Sin embargo, tal realización puntual deberá tener en consideración de modo específico el riesgo al que esto podría conllevar; concretamente, permitir que ciertos grupos de la sociedad se "nutran" del Estado, convirtiéndolo automáticamente en un "Estado económico", profundamente criticado en la primera generación ordoliberal.

\subsection{Rasgos esenciales de un concepto en continua transformación}

En el presente trabajo se ha puesto de manifiesto la variedad de interpretaciones existentes acerca del concepto de Constitución económica. El análisis desarrollado hasta aquí ha mantenido una perspectiva descriptiva enfocada específicamente sobre los elementos teóricos originarios del término (ordoliberalismo), estudiándose asimismo la posible aportación teórica de una definición en sentido formal, así como la interpretación sustantiva predominante a nivel europeo (economía social de mercado). En los epígrafes que siguen se desarrollará la segunda parte teórica del trabajo, esbozándose una propuesta conceptual referida a la dignidad humana como principio esencial de legitimidad, incardinado en la Constitución económica.

73 Por ejemplo, una congelación del precio del alquiler independientemente de la capacidad de pago de los inquilinos sería marktinkonform (en disconformidad con el mercado) por afectar a todo el mercado de vivienda, mientras que un sistema de ayuda para la renta de los pobres sería martkonform (de conformidad con el mercado), Alfred MÜLLER-ARMACK, op. cit. (p. 84). 
Desde esta perspectiva, el concepto aquí analizado contendría tres rasgos fundamentales: una estabilidad vital que permitiría el acomodo jurídico positivo al tiempo y al espacio de referencia; autonomía derivada del específico mecanismo de protección de la libertad económica en sentido estricto (el mercado) y, por último, una interconexión inherente con la Constitución política, al existir dos ámbitos materiales de intersección (la sociedad civil y la especial naturaleza axiológica de las normas constitucionales). Toda esta construcción permitiría delimitar, finalmente, las dos funciones primordiales de la Constitución económica. La primera (constitutiva) se refiere estrictamente al mercado como herramienta de garantía y expansión de la libertad económica; la segunda (potenciadora) persigue armonizar y reforzar las vertientes complementarias de la libertad humana (económica, política y privada). Por último, cabe mencionar que las funciones identificadas no evolucionan de modo causal-temporal, sino de manera dinámica e imprevisible; por lo que su distinción se realiza solamente a efectos analíticos.

\subsubsection{Un concepto que trasciende el ámbito temporal e ideológico de las definiciones concretas}

La diversidad de definiciones existentes acerca del alcance teórico de la Constitución económica pone de manifiesto la necesidad de formular un concepto apto para permanecer estable a los cambios ideológicos y fácticos que condicionan en cada momento histórico su significado concreto. De este modo, la atribución de un sentido invariable se podría realizar mediante la extracción teórica de un posible núcleo de la Constitución económica, una esencia que permita su identificación, independientemente de la configuración textual otorgada en el Derecho positivo.

El requisito intrínseco de traspasar los factores ideológicos y fácticos momentáneos no implica una indiferencia hacia los mismos; la propia identificación de un sentido esencial de la Constitución económica debe mantener la capacidad de responder a los cambios naturales de la realidad material. En otras palabras, se trata de un concepto cuyo núcleo inmune al paso del tiempo debe integrar una flexibilidad suficiente para responder a retos futuros. En efecto, la virtud conceptual de la Constitución económica se manifiesta no tanto en su significado concreto en un momento dado, sino en su característica de estabilidad vital, con vocación de adaptación a las circunstancias externas.

\subsubsection{Un concepto jurídico}

El requerimiento de estabilidad de la Constitución económica resulta coherente con su configuración como concepto jurídico, destinado a regular las relaciones económicas y el proceso de producción en un determinado espacio geográfico. Desde esta perspectiva, la fuerza vinculante de las normas ordenadoras de la realidad económica derivaría, en primer lugar y según un criterio positivista, de la aprobación de las 
normas de acuerdo con los procedimientos establecidos en la Constitución política. En este sentido, el criterio legitimador fundamental que otorgaría fuerza normativa a la Constitución económica residiría en su vocación de resolución de controversias —función clásica del Derecho- de naturaleza socioeconómica.

Sin embargo, como toda norma, la Constitución económica tampoco puede escaparse a consideraciones que vayan más allá de la mera obligatoriedad jurídica. ${ }^{74}$ En efecto, el presente trabajo parte de la premisa metodológica según la cual la fuerza normativa de la Constitución económica no se agota en su sentido positivista; ni siquiera en su vocación de solución de conflictos. La compleja realidad sobre la cual esta norma proyecta su pretensión orientadora requiere integrar en el discurso jurídico también las consideraciones de naturaleza substantiva, fundamentándose de este modo su normatividad en la aceptación social ${ }^{75}$, que deriva, entre otras, también de la adecuación moral de la Constitución económica a los requisitos de una "ordenación buena y justa” de la sociedad ${ }^{76}$, en su concreta esfera de regulación jurídica.

En pocas palabras, la normatividad de la Constitución económica no puede reducirse a un carácter formal de obligatoriedad. Pues, de inmediato se observará que la pretensión de vigencia de esta norma depende directamente de su capacidad estructuradora y orientadora de la realidad económica. Resulta esencial destacar, en este punto, que tal realidad no se encuentra en aislamiento absoluto respecto del resto de vertientes de la realidad humana — política, individual—y que, además, todas ellas se interrelacionan de manera imprevisible, y se desarrollan autónomamente con igual imprevisibilidad. De este modo, sería simplemente ilusorio atribuir una consecuencia de independencia normativa a las Constituciones económica y política, dado que sus realidades constitucionales se intersectan constantemente, condicionando de modo recíproco la consecución de los objetivos que justifican la propia existencia de estas normas.

74 "No hay norma que pueda garantizarse a sí misma", Uwe VOLKMANN, Elementos de una teoría de la Constitución alemana, trad. I. Gutiérrez Gutiérrez, Marcial Pons, Madrid, 2019 (p. 311). En igual sentido, Richard H. Jr. FALLON, "Legitimacy and the Constitution", Harvard Law Review, vol. 118, núm. 6, abril, 2005, pp. 1787-1853 (esp. pp. 1794-1813). Disponible en: https://www.jstor.org/ stablel4093285? seq=1\%cid=pdf-reference\#references_tab_contents (última consulta: 10.04.202). Sobre la "humanidad" como fundamento último de la soberanía Anne PETERS, "Humanity as the A and $\Omega$ of Sovereignty", The European Journal of International Law, vol. 20, núm. 3, 2009, pp. 513-544: "State sovereignty is not only - as in the meanwhile canonical view - limited by human rights, but is from the outset determined and qualified by humanity, and has a legal value only to the extent that it respects human rights, interests, and needs. It has thus been humanized' (p. 514).

75 Entre los positivistas que retrotraen la vinculatoriedad jurídica a la aceptación social: Herbert L. A. HART, The Concept of Law, Oxford University Press, Oxford, $3^{\mathrm{a}}$ ed., 2012.

76 En palabras de Hesse, solo es orden jurídico aquél "de un contenido determinado, recto, y por ello legítimo”, Konrad HESSE, Escritos de Derecho Constitucional, trad. P. Cruz Villalón/M. Azpitarte Sánchez, Centro de Estudios Políticos y Constitucionales, Madrid, 2012 (p. 43). Como toda consideración metodológica, la presente también revela y condiciona los rasgos teóricos del concepto aquí estudiado, pues "los métodos [...] desvelan sin saberlo conclusiones que a veces pretenden no conocer aún. Las últimas páginas de un libro están ya en las primeras, por ejemplo. Este nudo es inevitable”, Albert CAMUS, El mito de Sísifo, Alianza Editorial, E-book, Apple Distribution International Ltd, 2015 (p. 28). 
Lo anterior permite ofrecer una interpretación armoniosa de las premisas teóricas del concepto aquí estudiado, en sus dos vertientes aparentemente contrapuestas. Ya se ha visto que, en la construcción ordoliberal, la autonomía conceptual de la Constitución económica se fundamentaba en la separación de las esferas económica y política; mientras que el principio de neutralidad ideológica permitía identificar la Constitución económica de acuerdo con un criterio de especificidad material (política socioeconómica), rechazándose con ello —o como mínimo, disminuyéndose- la autonomía de este concepto respecto de la esfera estrictamente política. Reconocer que la normatividad de la Constitución económica depende también de su adecuación a consideraciones de justicia social ${ }^{77}$, y que la realidad sobre la que despliega su eficacia se encuentra en permanente intersección — aunque no en plena identidad- con la realidad constitucional de la Constitución política, permite admitir que autonomía no significa separación; o, lo que es lo mismo, la autonomía no excluye la interconexión.

De este modo, es posible entender simultáneamente que, a pesar de su autonomía conceptual, la propia pretensión de normatividad de la Constitución económica integra condicionantes referidos a la justicia social. Además, la permanente interrelación entre las realidades económica y política despliega también efectos sobre la normatividad de la Constitución política, influyendo externamente sobre su capacidad interna de vincular. Autonomía significa, entonces, reconocer que cada Constitución mantiene una fórmula propia de protección de la libertad humana (el mercado, de un lado, y la organización política, de otro), en función de la esfera primordial de garantía y desenvolvimiento de esta libertad (libertad económica en el mercado; libertad política en la Comunidad).

Sin embargo, también significa admitir que todas las vertientes de la libertad humana se interrelacionan, se condicionan, y se refuerzan recíprocamente. De ahí que lo esencial de las Constituciones no sea el medio, sino el objetivo perseguido (la garantía de la libertad). ${ }^{78} \mathrm{O}$, mejor dicho, es el propio objetivo el que justifica la constitucionalización de los medios; de modo que el mercado se convierte en un simple instrumento de protección de la libertad, reconocido en la Constitución económica. A la vez que la garantía de ese medio es fundamental para la consecución del objetivo, se pone de manifiesto la necesidad de re-identificar el bien jurídico primordialmente protegido en la Constitución económica, sometiéndose el mercado a los requerimientos de la libertad humana a través del Derecho (constitucional).

77 Sobre la relevancia de la justicia derivada primordialmente del consenso (de los destinatarios de las normas), y — solo en un segundo momento — de su dimensión axiológica: Geoffrey BRENNAN; James M. BUCHANAN, The reason of rules. Constitutional political economy, Cambridge University Press, Cambridge, 1985 (pp. 97-98).

78 "Las Constituciones, esencialmente, han surgido de la experiencia, el abuso del poder en detrimento de los ciudadanos. Las formas de abusar del poder cambian; la Constitución debe responder y "dirigir" de nuevo adecuadamente [...] como Constitución de la libertad", Peter HÄBERLE, Tiempo y Constitución, cit. (pp. 29-32). Sobre la libertad como fundamento último en la propuesta de una $A u-$ toridad Pública Internacional, Armin VON BOGDANDY; Matthias GOLDMANN; Ingo VENZKE, "From Public International To International Public Law: Translating World Public Opinion Into International Public Authority", MPIL Research Paper Series, núm. 2, 2016 (p. 32). 


\subsubsection{Constitución politica y Constitución económica: ámbitos de intersección}

A pesar de tratarse de vertientes distintas de la libertad (y de la realidad), la Constitución económica se vincula de manera directa con la Constitución política si se tiene en cuenta que los factores socioeconómicos son un pilar central del contexto fáctico subyacente a la Constitución (política). Esta idea se deriva de una precomprensión metodológica en relación con el concepto de Constitución, que, más allá del texto formal, engloba también el contexto social sobre el cual esta norma pretende desplegar su eficacia, transformándose en "la ordenación de la justicia en el contexto político". ${ }^{79}$

Tal premisa metodológica obliga explicar sus implicaciones más relevantes para el concepto aquí estudiado. En efecto, son dos las ideas esenciales que permiten identificar con mayor eficiencia los ámbitos de intersección de las Constituciones política y económica: de un lado, la real extensión del espacio de irradiación normativa de la Constitución política (ámbito social); de otro, la especial naturaleza de su contenido (ámbito axiológico). La identificación de estos ámbitos de intersección es fundamental para entender cómo, a pesar de su autonomía, cada una de las dos Constituciones condiciona profundamente la fuerza normativa de la otra.

Para un mejor entendimiento de estas consideraciones, conviene realizar a continuación dos reflexiones complementarias. En primer lugar, la Constitución (política) se puede delimitar en función de su relación (intrínseca y dinámica) con la Constitución positiva: "neither as a field of extra-juridic knowledge, nor as a straightforward conveyor-belt of legal norms but as internally and dynamically related to the formal constitution". ${ }^{80}$ En segundo lugar y en adición a lo primero, este mismo concepto se define por la existencia de cuatro factores que componen, alimentan y se retroalimentan a su vez del orden constitucional: la unidad política; un conjunto de instituciones (políticas); las relaciones sociales y los objetivos políticos fundamentales. ${ }^{81}$

La adopción de una definición más amplia acerca del concepto de Constitución no solo permite superar la insuficiencia del texto constitucional a los efectos de su interpretación (dada su clásica formulación abierta), sino que tiene también un alto potencial explicativo respecto de las fronteras imprecisas que diferencian los conceptos de Constitución (política) y Constitución económica. En este sentido, la irradiación normativa de la Constitución política sobre los cuatro elementos antes mencionados demuestra cómo el carácter vinculante de la norma fundamental no depende y no se proyecta de forma autorreferencial meramente sobre el texto. Al contrario, se requiere una interpretación holística apta para justificar la fuerza normativa de la Constitución política, a la luz de su capacidad de garantizar — simultáneamentela unidad política, la estabilidad de sus instituciones fundamentales, los objetivos po-

79 Uwe VOLKMANN, op. cit. (p. 28 y passim).

${ }^{80}$ Marco GOLDONI; Michael A. WILKINSON, "The Material Constitution", The Modern Law Review, vol. 81, núm. 4, 2018 (julio), pp. 567-597 (p. 569).

81 Ibid. 
líticos esenciales y, sobre todo (en lo que aquí interesa), la existencia de un contexto social favorable sobre el cual pueda desplegar tal normatividad.

En pocas palabras, el orden constitucional comprende e irradia también la realidad socioeconómica subyacente al Derecho positivo. Sin embargo, la integración del contexto social como factor esencial en el concepto de Constitución (política) no se traduce en un cambio cualitativo de la sociedad en factor predominantemente político; del mismo modo que la dependencia de la Constitución política de las circunstancias económicas no transforma automáticamente la naturaleza política de la Constitución en carácter económico. ${ }^{82}$

Reflexionar sobre la real extensión de la Constitución (política) significa reconocer que la ordenación política de la sociedad por medio de la norma fundamental debe tomar en consideración, como factor decisivo, a la propia sociedad. Supone, en definitiva, volver la mirada sobre una de las preguntas clásicas del constitucionalismo, referida a la relación entre el Estado y la sociedad, y admitir que la Constitución política es solo una de las respuestas posibles a la "pregunta decisiva [acerca del] modo de vincular al Estado y la Sociedad”. ${ }^{83}$ La Constitución económica puede ser, a su vez, una respuesta adicional a esta pregunta decisiva, en tanto en cuanto se admita la existencia de esferas autónomas de la realidad vitalmente interconectadas, pero no por ello idénticas; autónomas, pero no por ello mutuamente excluyentes. Todo lo anterior permitiría identificar, finalmente, el primer ámbito material de intersección entre las Constituciones política y económica, esto es, la sociedad civil.

Se define este ámbito por su carácter híbrido público-privado, al ser la sociedad una esfera necesaria de la realidad que permite la transición del individuo desde el espacio subjetivo (privado) hacia el ámbito público (político). En este sentido, la sociedad cobra existencia en forma de realidad objetiva a través de la puesta en común de intereses privados; siendo así una apariencia común de la supervivencia humana individual. La esfera social se convierte, de este modo, en el pilar objetivo (como realidad compartida) que sostiene la promesa mutua de la autoorganización política ${ }^{84}$.

Pero esta esfera social como realidad compartida (o pre-política) no es solo una base material para la Constitución política, sino también para la Constitución económica. En efecto, el mercado es una fórmula específica de conformación común de la realidad, en tanto que el dinero - medio esencial de la vida económica - solo puede adquirir valor determinado en presencia de otros participantes de la vida humana. ${ }^{85}$

82 "Although study of political economy is essential for understanding the material formation and reproduction of society (its metaphorical 'backbone'), the structure and content of the material constitution is not economically determined', Marco GOLDONI; Michael A. WILKINSON, op. cit. (p. 587).

83 Konrad HESSE, op. cit. (p. 130).

84 Hannah ARENDT, The Human Condition, The University of Chicago Press, Chicago \& London, $2^{\text {a ed., }} 2018$ (pp. 33, 46, 50).

${ }^{85}$ Ibid. (p. 164). 
Como ya se ha mencionado, existe un segundo ámbito de interacción entre la Constitución política y la económica, esta vez derivado de la especial naturaleza del contenido de la Constitución política. Se trata de un contenido con notable carga moral, al residir la normatividad de la Constitución, en última instancia, en su capacidad de orientar y ordenar políticamente la sociedad según una concepción básica de justicia. ${ }^{86}$ Esta idea se pone de manifiesto en los múltiples preceptos de contenido ideal de la Constitución positiva, que finalmente se pueden interpretar como "concretizaciones del principio de la dignidad humana en ámbitos específicos". ${ }^{87}$

Pero la extracción o la existencia de este contenido de especial naturaleza no se debe a su pertenencia a la organización política, sino a su importancia vital para la convivencia humana, al ser un criterio ético superior que legitima la juridificación del poder político. En otras palabras, el valor de la dignidad humana no es típico primordialmente de las Constituciones políticas, sino que es un valor necesario para la propia supervivencia en común de las personas. Siendo cierto, no obstante, que es la propia inserción de este valor en la ordenación política de la sociedad la que justifica también la normatividad de la Constitución política. Al ser el principio de la dignidad humana un criterio de ordenación de lo común (y posteriormente de lo público), y al ser el mercado solo una parte de lo común, su regulación jurídicoconstitucional requiere, a los efectos de su validez axiológica, el acomodo del mercado a este principio.

\subsubsection{Un concepto orientado hacia la protección de la libertad humana: funciones de la Constitución económica}

Las características fundamentales de la Constitución económica anteriormente explicadas permiten avanzar en el recorrido conceptual, siendo necesario reflexionar, en adelante, acerca de las funciones que desarrollan de manera concreta el criterio último de normatividad ya identificado. En particular, se propone la identificación del esqueleto funcional básico de la Constitución económica, desde la perspectiva de la protección de la libertad.

El enfoque teórico sobre las funciones de la Constitución con el fin de determinar su alcance normativo no representa una innovación metodológica. ${ }^{88}$ Más bien, es la

${ }^{86}$ Uwe VOLKMANN, op. cit. (esp. pp. 241 y ss).

87 Ibid. (p. 248). Clásicamente sobre la dignidad humana como principio legitimador supremo, Günther DÜRIG, "Der Grundrechtssatz von der Menschenwürde: Entwurf eines praktikablen Wertsystems der Grundrechte aus Art. 1 Abs. I in Verbindung mit Art. 19 Abs. II des Grundgesetzes", Archiv des öffentlichen Rechts, vol. 81, núm. 2, 1956 (pp. 117-157). Disponible en: https://www. jstor.org/stable/44303797? seq=1\#metadata info_tab_contents (última consulta: 10.04.2021).

88 Véase el texto clásico de Rudolf SMEND, "Constitución y Derecho Constitucional" [1928], en: La controversia Smend/Kelsen sobre la integración en la Constitución y el Estado durante la República de Weimar, trad. J.M. Beneyto/J.A. García Amado, Tecnos, Madrid, 2019 [identificando los tres tipos de integración: personal, funcional y material (pp. 29-59)]. En el ámbito anglosajón se puede consultar, más recientemente, Ernest A. YOUNG, "The Constitution Outside the Constitution", The Yale Law 
propia variedad de sentidos del término "función" la que requiere aclarar la definición aquí empleada, i.e. tareas cuyo cumplimiento está encomendado a la Constitución de acuerdo con las expectativas (de justicia) de la sociedad. ${ }^{89}$ Esta interpretación resulta especialmente congruente con la premisa básica de este trabajo, pues permite incidir, de entrada, sobre la dimensión axiológica de la Constitución económica, esbozándose meramente el mapa conceptual respecto de los concretos elementos de Derecho positivo. En este sentido, el análisis relativo a la adecuación y congruencia de tales elementos respecto del esqueleto conceptual de la Constitución económica se configura como objetivo esencial de futuras investigaciones doctrinales.

La delimitación funcional del concepto aquí analizado se puede llevar a cabo mediante el estudio de los efectos esenciales ${ }^{90}$ de la regulación jurídica. Partiendo del principio de base en el que se fundamenta la normatividad de la Constitución económica (la dignidad humana), se pueden distinguir analíticamente dos funciones básicas mediante las cuales se lleva a cabo el objetivo esencial de protección de la libertad: la función constitutiva y la función potenciadora o armonizadora. Estas funciones proyectan, a su vez, manifestaciones adicionales referidas, de un lado, a la integración económica en sentido estricto (libertad como posibilidad jurídica) y de otro, la integración sustantiva (libertad como capacidad).

\subsubsection{Función constitutiva}

El primer efecto esencial de la regulación se refiere a la constitución jurídica del mercado como herramienta de garantía de la libertad económica, mediante la identificación y la protección de sus piezas básicas. ${ }^{91}$ En este aspecto, lo fundamental reside en que la Constitución económica reconoce el papel protector del mercado; ya que su ausencia se traduciría en una negación de posibilidades para el desenvolvimiento autónomo del individuo, en el ámbito económico de lo común. Como se puede observar, el centro de interés de la Constitución económica se mantiene sobre la libertad económica como un fin en sí misma, sin que sea necesario tomar en consideración aquí su interrelación con el resto de vertientes de la libertad humana.

La función constitutiva se vincula a la idea liberal clásica según la cual, independientemente del nivel de eficiencia del mercado para asegurar la realización de los planes individuales, la mera existencia de un ámbito libre de intercambio, produc-

\footnotetext{
Journal, núm. 117, 2007, pp. 408-473, que emplea la perspectiva funcional para identificar las normas "ordinarias" de contenido constitucional.

89 Uwe VOLKMANN, op. cit. (pp. 63-64).

90 Ibid. (p. 331), hablándose de "dimensiones de la normatividad" de la Constitución.

91 Fundamentalmente, los principios de libre empresa y de economía de mercado (art. $38 \mathrm{CE}$ ), la garantía de la propiedad privada (art. $33 \mathrm{CE)}$ ) así como los derechos económicos reconocidos en el Derecho de la Unión Europea, en la modalidad de principios generales del Derecho (art. 6.3 TUE) o como derechos explícitamente recogidos en la Carta de Derechos Fundamentales de la Unión Europea (art. 6.1 TUE).
} 
ción, inversión y consumo representa el presupuesto de hecho de la libertad económica. El significado axiológico de la función constitutiva se reduce a la identificación de la libertad económica como valor en sí mismo para la vida humana ${ }^{92}$, dotando también de autonomía al mercado.

Dando un paso más, la expansión cuantitativa de las opciones reales de los agentes para entablar relaciones económicas mediante la apertura y la integración de los mercados también se traduciría en un refuerzo de la libertad económica. En efecto, la vocación integradora de la Constitución económica se manifiesta de forma específica en el contexto europeo, al ser la construcción del mercado único un objetivo primordial reconocido en los Tratados fundacionales de la Unión. ${ }^{93}$ Sin considerar aquí las fórmulas precisas de integración ${ }^{94}$, es posible afirmar que la expansión del horizonte jurídico de posibilidades económicas aumenta de forma incontestable el ejercicio de la libertad económica, en cuanto que multiplica y diversifica las opciones existentes en el mercado.

Se observa, por tanto, que la configuración conceptual de la Constitución económica de acuerdo con la idea esencial de protección de la libertad económica engloba también una alta compatibilidad con el proceso de integración europea y con la característica de unidad del mercado ${ }^{95}$. Especialmente propicias para dar respuesta a las

${ }_{92}$ "The point at issue is [...] the availability of freedom (no matter whether the freedom is aimed at self-interest or at some other objective)", Amartya SEN, Development as Freedom, Knopf Doubleday Publishing Group, Kindle Edition (p. 118).

93 Art. 3.3 del tUe LISBOA. La expansión y apertura de los mercados nacionales son características esenciales del fenómeno de globalización económica; el sueño de construir un "mundo del comercio sin muros" se ha venido impulsando ya desde los inicios de siglo xx, siendo de especial relevancia en este sentido la creación de la Cámara Internacional del Comercio (ICC, por sus siglas en inglés) en París, 1920. Este fenómeno se ha consolidado a nivel internacional especialmente tras la Segunda Guerra Mundial, a través de las políticas conocidas como "El Consenso de Washington". Sobre la globalización económica como proyecto político neoliberal impulsado a través de las instituciones internacionales (y que hacen uso del Estado para llevarlo a cabo): Quinn SLOBODIAN, Globalists. The End of Empire and the Birth of Neoliberalism, Harvard University Press, Cambridge-Massachusetts-London-England, 2018 (p. 49).

${ }_{94}$ Según la clásica definición de Fritz W. SCHARPF, Gobernar en Europa. ¿Eficaz y democráticamente?, trad. J. Alborés, Alianza Editorial, 2000 (esp. pp. 59 y ss.), se trataría de mecanismos de integración negativa positiva.

${ }^{95}$ Determinar la existencia de compatibilidad no explica también el nivel admisible de compatibilidad. En este sentido, una parte relevante de la doctrina defiende la existencia de una Constitución económica "compuesta" por la Constitución económica nacional y la Constitución económica de la Unión. Armin HATJE, op. cit. (p. 593). Las diversas interpretaciones se extraen a la luz de la metodología de base empleada para definir la propia Unión Europea. En cuanto al constitucionalismo multinivel (Verfassungsverbund), Armin VON BOGDANDY; Jürgen BAST (eds.), Principles of European Constitutional Law, cit:; Ingolf PERNICE, "Does Europe Need a Constitution? Achievements and Challenges after Lisbon", en Anthony ARNULL; Catherine BARNARD; Michael DOUGAN; Eleanor SPAVENTA (eds.): A Constitutional Order of States?, Hart Publishing, Oxford-Portland, 2011 (pp. $75-$ 98). En defensa de una homogeneidad ideal-sustantiva que mantiene intactos, sin embargo, los distintos espacios jurídicos ("Derecho común europeo"), Peter HÄBERLE, ¿Tienen España y Europa una Constitución?, trad. M. Azpitarte Sánchez, Fundación El Monte, Sevilla, 2004. 
expectativas de aumento de la libertad económica resultarían, entonces, las libertades fundamentales del mercado único (mercancías, personas, servicios y capitales ${ }^{96}$ ) y la prohibición de las prácticas empresariales ${ }^{97}$ y ayudas estatales ${ }^{98}$ que falsean la competencia; derivando todas ellas del principio básico de igualdad en el ejercicio de la actividad económica ${ }^{99}$.

Las consideraciones anteriores no equivalen, sin embargo, a una pretensión de abandono absoluto de la libertad económica al mercado; y, especialmente, la virtud instrumental del mercado respecto de la libertad económica no debe llevar a una prevalencia económica sobre el resto de vertientes de la libertad humana. Pues, como ya se ha indicado, es precisamente la interrelación armónica de todas estas facetas la que otorga, en última instancia, fuerza normativa a las Constituciones económica y política.

Retomando la justificación originaria (ordoliberal) acerca de la vinculatoriedad jurídica de la Constitución económica, y aun reconociendo la importancia y la autonomía del mercado, las esferas de intersección (social y axiológica) requieren superar las consideraciones referidas estrictamente al mercado (justicia derivada de la necesidad, utilidad y razonabilidad), con el objetivo de acomodar la libertad económica a sus facetas adicionales. Este acomodo no solo tiene la capacidad de reforzar la libertad económica en sentido estricto (ofreciéndole una sustancia adicional), sino también de potenciar el resto de vertientes de la libertad humana; de modo que la Constitución política no encuentre obstáculos externos que disminuyan su fuerza normativa.

\subsubsection{Función potenciadora}

La función potenciadora de la Constitución económica pretende superar la definición de la libertad económica en sentido estricto (como posibilidad jurídicamente garantizada para el desenvolvimiento en el mercado), centrándose en su aspecto sustantivo, definido como capacidad, i.e. las condiciones materiales que hacen posible la existencia humana digna. ${ }^{100} \mathrm{La}$ diferencia analítica entre la función constitutiva y la función potenciadora consiste en que la segunda desvela una idoneidad específica para reforzar y garantizar tanto la esfera económica de la libertad, como el resto de sus vertientes; siendo de especial interés aquí, la libertad política.

96 Art. 26.2 TFUE.

97 Art. 101 TFUE.

98 Art. 107 TFUE.

99 En igual sentido se ha pronunciado también el Tribunal Constitucional español, en reiterada jurisprudencia a partir de la STC 88/1986, de 1 de julio (BOE, núm. 174, de 22 de julio), FJ 4.

100 Sin estas "condiciones materiales externas del cuerpo y la vida", "el hombre como tal no tiene lo que constituye su dignidad, es decir, la capacidad de elevarse por encima del entorno impersonal en libre decisión”, Günther DÜRIG, op. cit. (p. 131). 
La importancia real de esta función de la Constitución económica solo se puede comprender a través de reflexiones concretas sobre los modos de mutua condicionalidad. En este sentido, un primer ejemplo podría ser la ausencia de ingresos mínimos (pobreza). Mientras que este factor condiciona la propia realización de la libertad económica (participación libre en el mercado, siquiera bajo la figura del consumidor), produce asimismo consecuencias fundamentales sobre los derechos básicos de la esfera política (entre otros, el acceso a los medios de comunicación, correspondiente a la libertad de recibir información).

Dando un paso más, se podría afirmar que la intensidad de las necesidades económicas aumenta, en lugar de disminuir, la urgencia de las libertades políticas. Ello porque, a través de los derechos fundamentales políticos, no solo se consolida el debate público — de obligada existencia en el Estado constitucional democrático-, o se reclaman respuestas políticas en relación con las necesidades económicas de los ciudadanos, sino que también se hace posible la propia conceptualización y comprensión de estas necesidades económicas básicas: "ii]t can indeed be argued that a proper understanding of what economic needs are - their content and their force - requires discussion and exchange". ${ }^{101}$

De igual manera, las oportunidades sociales (por ejemplo, la sanidad o la educación ${ }^{102}$ ) son factores de creación y consolidación de todas las esferas de la libertad (económica, política, privada). A modo de ejemplo, se podría pensar en la relevancia de una vida sana para la libertad privada; pero, a la vez, una baja tasa de mortalidad y morbilidad otorgarían un mayor nivel de normatividad a la Constitución política, en tanto que aumentan la seguridad del individuo sobre la vida misma y con ello, la confianza en la autoridad política. De forma análoga, la educación refuerza a la vez, la capacidad para participar en el mercado (teniendo en cuenta de forma específica el aumento de la técnica y su importancia en un mundo cada vez más interconectado) pero también la capacidad de participación política (por ejemplo, leer y comprender la información presentada en los medios de comunicación). ${ }^{103}$

Desde esta perspectiva, además de ser un fin en sí mismo de la Constitución económica, la libertad económica se presenta simultáneamente como instrumento de potenciación del resto de libertades que, sin definirse propiamente como económicas, son relevantes a su vez para consolidar la capacidad de ejercer la libertad económica. De este modo, la Constitución económica se desprende, en su esencia conceptual, de la premisa liberal clásica (y ordoliberal) relativa a una presunta hostilidad inherente entre la economía y la política. ${ }^{104}$

El mutuo refuerzo de libertades observado en el nivel máximo de intersección de los ámbitos social y axiológico requiere integrar en la Constitución económica una función apta para dar respuesta jurídica a las necesidades sociales y expectati-

\footnotetext{
101 Amartya SEN, op. cit. (p. 153).

102 Ibid. (p. 39).

103 Ibid.

104 Ibid. (p. 3).
} 
vas de justicia que fundamentan su fuerza normativa. La función potenciadora aquí mencionada proyecta un efecto de compensación respecto de la libertad económica en sentido estricto (respondiendo a las privaciones de libertad derivadas del propio funcionamiento del mercado); a la vez que armoniza y refuerza externamente los requisitos de normatividad de la Constitución política. De este modo, la función potenciadora respondería, por analogía, al principio constitucional del Estado social; siendo este un principio esencial del constitucionalismo como instrumento para garantizar y compensar la fragilidad de la libertad humana. ${ }^{105}$

\section{CONCLUSIONES}

En este texto se ha formulado una propuesta conceptual de Constitución económica, distinta de las principales definiciones existentes en la literatura jurídica europea. Los rasgos que la diferencian se deben, sobre todo, a la propia ontología jurídica desde la cual estos se formulan. En concreto, el trabajo se adhiere a una visión del Derecho como "orden justo" de la sociedad. Esta idea determina los dos elementos esenciales de la Constitución económica: de un lado, su legitimidad; de otro, la segunda función, denominada "potenciadora".

Al considerarse que la vertiente axiológica — vinculada al principio de la dignidad humana - pertenece de forma intrínseca a la disciplina jurídica, y por ende a la Constitución económica, se rechazan las propuestas teóricas puramente positivistas. Sin embargo, la autonomía conceptual de la Constitución económica requiere excluir también las propuestas alternativas que se basen exclusivamente en el principio democrático. Se demuestra, asimismo, que la superación de una visión formalista del Derecho no requiere automáticamente aceptar como carácter distintivo de las normas jurídicas, la esencia política; pero sí su relación con la realidad social que pretenden regular.

Por un lado, la definición de la Constitución económica en el sentido de un conjunto de normas que regulan la actividad económica en un determinado territorio resulta insatisfactoria para justificar la propia existencia del concepto estudiado. En términos de legitimidad, esta descripción presenta los déficits bien conocidos de la teoría de la Constitución desarrollada a finales de siglo XIX y principios de siglo xx. Más concretamente, a los efectos de legitimar la Constitución económica desde la perspectiva mencionada, sería necesario recurrir a la propia Constitución política o, si se quiere buscar más allá, a una norma hipotética. En cualquiera de los casos, la normatividad de la Constitución económica mantendría un carácter exclusivamente imperativo, desplegando, pues, su vinculatoriedad independientemente de la aceptación social. En términos funcionales, la Constitución económica definida exclusiva-

105 Una propuesta de "constitucionalismo global social" que presenta el principio constitucional del Estado social como una "herencia constitucional compartida", no necesariamente vinculado a la organización política estatal, Anne PETERS, "Global Constitutionalism: The Social Dimension”, MPIL Research Paper Series, núm. 25, 2017, p. 37. 
mente desde un punto de vista formal se traduciría en la mera ordenación de factores económicos, sin desvelar, no obstante, un sentido concreto de esta ordenación, más allá del objetivo de conseguir una cierta unidad regulatoria.

Por otro lado, el rechazo de la Constitución económica interpretada como deferencia constitucionalizada hacia el legislador democrático se debe a la consiguiente pérdida de autonomía conceptual de la Constitución económica. Además, al ser el Estado la única organización política que presenta — según la teoría constitucional clásica - el "máximo" nivel de legitimidad democrática posible, se introduciría una dependencia forzada del Derecho (y más concretamente, de la Constitución económica) respecto del legislador estatal, a la vez que un hiper-protagonismo del Estado en la producción jurídica. Se trataría, sin embargo, de una narrativa que difícilmente se pueda sostener en la actualidad, aun reconociéndose la relevante presencia del Estado como actor en la escena internacional.

La ventaja de una Constitución económica interpretada como deferencia constitucionalizada hacia el legislador consistiría en que, frente a la visión ordoliberal, esta favorecería una mayor garantía de la igualdad material - elemento clave de una existencia humanamente digna-. Sin embargo, la Constitución económica así definida se identificaría con una mera parcela específica de la Constitución política. Como consecuencia de lo anterior, el concepto de Constitución económica debería incorporar las ficciones más debatidas — y quizás más problemáticas para un Derecho público que pretenda superar las fronteras nacionales - de la teoría moderna del Estado: el pueblo y su presunta homogeneidad.

Por último, en el trabajo se defiende la desvinculación conceptual de las Constituciones económica y política, lo que implica aceptar una separación funcional entre el mercado y la política. En particular, esta diferenciación presenta la ventaja de una mayor apertura y congruencia de la Constitución económica con los ordenamientos jurídicos supranacional e internacional, a la vez que una garantía más eficiente de los derechos fundamentales de carácter económico. Sin embargo, esto no debe llevar a la preeminencia absoluta del mercado sobre la democracia. Pues en el Estado constitucional no puede tener cabida una Constitución económica que ponga en peligro a la democracia o, como en el caso ordoliberal de primera generación, justifique su autonomía conceptual justamente a través de elementos antidemocráticos. En efecto, "la democracia no lo es todo, pero tampoco resulta renunciable". ${ }^{106}$

Alcanzar un equilibrio entre el principio democrático y el mercado libre representa uno de los retos más importantes del Derecho constitucional en la actualidad. En este trabajo se ha intentado dar cuenta de la compleja relación que siempre ha existido entre estos dos elementos. La definición aquí propuesta ha pretendido incorporar al Derecho constitucional económico el principio de la dignidad humana:

106 Ignacio GUTIÉRREZ GUTIÉRREZ, “Estado de Derecho y democracia más allá del Estado”, en Luis ARROYO JIMÉNEZ; Isaac MARTÍN DELGADO; Pablo MEIX CERECEDA (dirs.), Derecho Público Global. Fundamentos, actores y procesos, Iustel, Madrid, 2020 (p. 49). 
como criterio de legitimidad, pero también como criterio de resolución de posibles conflictos entre la Constitución económica y la Constitución política.

También tiene el constitucionalismo que huir de totalitarismos axiológicos. Sin embargo, en el marco de las construcciones conceptuales, el principio de la dignidad humana sea quizás el único para el cual merecería la pena arriesgar este reproche teórico, pues su irradiación queda plasmada sobre todas las vertientes de la realidad humana, independientemente del espacio geográfico, del avance técnico, de los cambios de ideología y de la sucesión de las generaciones.

\section{BIBLIOGRAFÍA}

Enoch ALBERTÍ ROVIRA, "La Constitución Económica de 1978. Reflexiones sobre la proyección de la Constitución sobre la economía en el XXV Aniversario de la Constitución española", Revista Española de Derecho Constitucional, año 24, núm. 71, mayo-agosto, 2004, pp. 123-159.

Hannah ARENDT, The Human Condition, The University of Chicago Press, Chicago \& London, 2a ed., 2018.

Miguel AZPITARTE SÁNCHEZ, "Alternancia y reconstrucción de la Constitución económica. Crónica política y legislativa del año 2011", Revista Española de Derecho Constitucional, núm. 94, eneroabril, 2012.

—, "Constitución del pluralismo y método jurídico", Teoría y Realidad Constitucional, núm. 21, 2008, pp. 447-459.

—, "El capitalismo sin mercado financiero y sus consecuencias sobre el Estado constitucional. Crónica política y legislativa del año 2012", Revista Española de Derecho Constitucional, núm. 100, eneroabril, 2014, pp. 151-179.

Francisco BALAGUER CALLEJÓN, "Crisis económica y crisis constitucional en Europa", Revista Española de Derecho Constitucional, núm. 98, mayo-agosto, 2013, pp. 91-107.

Isaiah BERLIN, "Two concepts of liberty", en Henry HARDY (ed): Liberty, Oxford University Press, New York, 2002.

Thomas BIEBRICHER; Frieder VOGELMANN (eds.): "Introduction", The birth of austerity. German ordoliberalism and contemporary neoliberalism, Rowman Littlefield International, London-New York, 2017.

Mark BLYTH: Austerity. The history of a dangerous idea, Oxford University Press, Oxford, 2015.

Franz BÖHM, "Decartelisation and De-concentration. A Problem for Specialists or a Fateful Question?", en Thomas BIEBRICHER; Frieder VOGELMANN (eds.), The birth of austerity. Rowman Littlefield International, London-New York, 2017, trad. M. Everson.

-, "Economic Ordering as a Problem of Economic Policy and a Problem of the Economic Constitution", en Thomas BIEBRICHER; Frieder VOGELMANN (eds.), The birth of austerity. Rowman Littlefield International, London-New York, 2017, trad. M. Everson.

Ernst W. BÖKENFÖRDE, "La democracia como principio constitucional", en Estudios sobre el Estado de Derecho y la Democracia, Trotta, Madrid, 2000.

Geoffrey BRENNAN; James M. BUCHANAN, The reason of rules. Constitutional political economy, Cambdridge University Press, Cambdrige, 1985.

Ottmar BÜHLER, "Texto de la Constitución alemana de agosto de 1919 y comentario sistemático a sus preceptos" [1929], trad. J. Rovira Armengol, en La Constitución de Weimar, Tecnos, Madrid, 2010.

Albert CAMUS, El mito de Sisifo, Alianza Editorial, E-book, Apple Distribution International Ltd, 2015.

Carlos DE CABO MARTÍN, "El Tratado Constitucional Europeo y el Constitucionalismo del Estado social”, Teoría y realidad constitucional, núm. 19, 2007, pp. 199-213. 
Fernando DE LOS RÍOS, El sentido humanista del socialismo, Biblioteca Nueva, Madrid, 2006. Ruth DUKES, "A Global Labour Constitution?", Queen's University Belfast School of Law, Enlighten: Publications, 2014, p. 4. Disponible en: http:/leprints.gla.ac.uk/76158/1/76158.pdf

Günter DÜRIG, "Der Grundrechtssatz von der Menschenwürde: Entwurf eines praktikablen Wertsystems der Grundrechte aus Art. 1 Abs. I in Verbindung mit Art. 19 Abs. II des Grundgesetzes", Archiv des öffentlichen Rechts, vol. 81, núm. 2, 1956, pp. 117-157. Disponible en: https://www.jstor. org/stable/44303797?seq=1\#metadata_info_tab_contents

Walter EUCKEN, "Competition as the Basic Principle of the Economic Constitution" [1942], en Thomas BIEBRICHER; Frieder VOGELMANN (eds.), The birth of austerity. Rowman Littlefield International, London-New York, 2017, trad. K. Tribe.

-, "Structural Transformations of the State and the Crisis of Capitalism", en Thomas BIEBRICHER; Frieder VOGELMANN (eds.), The birth of austerity. Rowman Littlefield International, LondonNew York, 2017, trad. K. Tribe.

—, "The Different Types of Economic System" [1940], en Thomas BIEBRICHER; Frieder VOGELMANN (eds.), The birth of austerity. Rowman Littlefield International, London-New York, 2017, trad. T.W. Hutchison.

Richard H. Jr. FALLON, "Legitimacy and the Constitution”, Harvard Law Review, vol. 118, núm. 6, abril, 2005, pp. 1787-1853. Disponible en: https://www.jstor.org/stable/4093285?seq=1 6 cid $=p d f-$ reference\#references_tab_contents

Lars P. FELD; Ekkehard A. KÖHLER; Daniel NIENTIEDT, "Ordoliberalism, pragmatism and the eurozone crisis: How the German tradition shaped economic policy in Europe", Freiburger Diskussionspapiere zur Ordungsökonomik, núm. 4, 2015. Disponible en: https://www.econstor.eu/handle/10419/111262

Ernst FORSTHOFF, El Estado de la sociedad industrial, trad. J. Nicolás Muñiz y L. López Guerra, CEPC, Madrid, 2013.

Michel FOUCAULT, The Birth of Biopolitics, Picador, New York, 2008.

Manuel GARCÍA PELAYO, "Consideraciones sobre las cláusulas económicas de la Constitución", en Manuel RAMÍREZ JIMÉNEZ (ed.), Estudios sobre la Constitución española de 1978, Zaragoza, Libros Pórtico, 1979.

David J. GERBER, "Constitutionalizing the Economy: German Neo-liberalism, Competition Law and the "New Europe»", American Journal of Comparative Law, vol. 42, núm. 25, 1994. Disponible en: https://scholarship.kentlaw.iit.edu/cgi/viewcontent.cgi?article $=1220$ \& $c o n t e x t=f a c \_s c h o l$

Matthias GOLDMANN, "Discretion, Not Rules: Post-Unitary Constitutional Pluralism in the Economic and Monetary Union”, Social Science Research Network, 30 de noviembre de 2017. Disponible en: https://ssrn.com/abstract $=3103641$

Marco GOLDONI; Michael A. WILKINSON, "The Material Constitution”, The Modern Law Review, vol. 81, núm. 4, 2018 (julio), pp. 567-597.

Angelo Jr. GOLIA, "Costituzionalismo sociale (teoria del)", en Rodolfo SACCO (dir.), Raffaele BIFULCO; Alfonso CELOTTO; Marco OLIVETTI (a cura di), Digesto delle Discipline Pubblicistiche, Agg. VII, UTET, Milano, 2017.

Luis I. GORDILLO PÉREZ, "Constitución económica, ordoliberalismo y Unión Europea. De un derecho económico nacional a uno europeo", Revista de Derecho UNED, núm. 23, 2018, pp. 249283.

Ignacio GUTIÉRREZ GUTIÉRREZ, "Debates sobre la metodología del Derecho público con la perspectiva de la multiculturalidad y la globalización", en Miguel Á. PRESNO LINERA (coord.), La metamorfosis del Estado y del Derecho, Fundamentos núm. 8, Junta General del Principado de Asturias, Oviedo, 2014.

—, "Estado de Derecho y democracia más allá del Estado", en Luis ARROYO JIMÉNEZ; Isaac MARTÍN DELGADO; Pablo MEIX CERECEDA (dirs.), Derecho Público Global. Fundamentos, actores $y$ procesos, Iustel, Madrid, 2020.

Peter HÄBERLE, ¿Tienen España y Europa una Constitución?, trad. M. Azpitarte Sánchez, Fundación El Monte, Sevilla, 2004.

—, Tiempo y Constitución, trad. J. L. León Vásquez, Palestra Editores, Lima, 2017. 
Herbert L. A. HART, The Concept of Law, Oxford University Press, Oxford, 3a ed., 2012.

Armin HATJE, "The Economic Constitution within the Internal Market", en Armin VON BOGDANDY; Jürgen BAST (eds.), Principles of European Constitutional Law, Hart, Oregon, 2010.

Friedrich A. HAYEK, Law, Legislation and Liberty, vol. II, The Mirage of Social Justice, Routledge, London, 1998.

Konrad HESSE, Escritos de Derecho Constitucional, trad. P. Cruz Villalón/M. Azpitarte Sánchez, Centro de Estudios Políticos y Constitucionales, Madrid, 2012.

Josef HIEN; Christian JOERGES (eds.), Ordoliberalism, Law and the Rule of Economics, Hart Publishing, Oxford, 2017.

Josef HIEN; Christian JOERGES, "Dead man walking? Current European interest in the ordoliberal tradition", European Law Journal, núm. 24, 2018, pp. 142-162.

Michael IOANNIDIS, "Europe's New Transformations: How the EU Economic Constitution changed during the eurozone crisis", Common Market Law Review, núm. 53, 2016, pp. 1237-1282.

Tony JUDT, Postguerra. Una historia de Europa desde 1945, trad. J. Cuellár y V. E. Gordo del Rey, Taurus, Madrid, 2005.

Stefan KOLEV, "Ordoliberalism", en Alain MARCIANO, Giovanni B. RAMELLO (eds.), Encyclopedia of Law and Economics, Springer, New York, 2017, https://doi.org/10.1007/978-1-4614-78836_618-3

John LOCKE, Second Treatise of Government, cap. IX, en Richard H. COX (ed.), E-book, Wiley-Blackwell.

Sebastián MARTÍN-RETORTILLO, Derecho Administrativo Económico, tomo I, Madrid, La Ley, 1991.

Aurelio MENÉNDEZ MENÉNDEZ, "Constitución, sistema económico y Derecho mercantil, Hacienda Pública Española, núm. 94, 1985.

Agustín J. MENÉNDEZ, "La mutación constitucional de la Unión Europea", Revista Española de Derecho Constitucional, núm. 96, septiembre-diciembre 2012, pp. 41-98.

Gabriel MORENO GONZÁLEZ, "Más allá de la Regla de Oro: las otras restricciones constitucionales al poder fiscal y presupuestario", Revista Española de Derecho Constitucional, núm. 115, 2019, pp. 205-227.

Costantino MORTATI, "Una valoración de conjunto sobre la experiencia de la Constitución de Weimar” [1946], trad. J. L. Aja Sánchez, en La Constitución de Weimar, Tecnos, Madrid, 2010.

Alfred MÜLLER-ARMACK, "The meaning of the social market economy", en Alan T. PEACOCK; Hans WILLGERODT (eds.) Germany's Social Market Economy: Origins and Evolution, Palgrave Macmillan, New York, 1989.

Robert NOZICK, Anarchy, State, and Utopia, Blackwell, Oxford UK \& Cambridge USA, 1999.

Ingolf PERNICE, "Does Europe Need a Constitution? Achievements and Challenges after Lisbon", en Anthony ARNULL; Catherine BARNARD; Michael DOUGAN; Eleanor SPAVENTA (eds.), $A$ Constitutional Order of States?, Hart Publishing, Oxford-Portland, 2011.

Anne PETERS, "Humanity as the A and $\Omega$ of Sovereignty", The European Journal of International Law, vol. 20, núm. 3, 2009, pp. 513-544.

—, "Global Constitutionalism: The Social Dimension", MPIL Research Paper Series, núm. 25, 2017.

Tony PROSSER, The Economic Constitution, Oxford University Press, New York, 2014.

Alexander von RÜSTOW, "General Sociological Causes of the Economic Disintegration and Possibilities of Reconstruction", en Thomas BIEBRICHER; Frieder VOGELMANN (eds.) The birth of austerity. Rowman Littlefield International, London-New York, 2017, trad. D. Steuer.

Fritz W. SCHARPF, Gobernar en Europa. ¿Eficaz y democráticamente?, trad. J. Alborés, Alianza Editorial, 2000.

Amartya SEN, Development as Freedom, Knopf Doubleday Publishing Group, Kindle Edition.

Hugo SINZHEIMER, Grundzüge des Arbeitsrechts, Fischer Verlag, Jena, 1927.

Quinn SLOBODIAN, Globalists. The End of Empire and the Birth of Neoliberalism, Harvard University Press, Cambridge-Massachusetts-London-England, 2018.

Rudolf SMEND, "Constitución y Derecho Constitucional" [1928], en La controversia Smend/Kelsen sobre la integración en la Constitución y el Estado durante la República de Weimar, trad. J.M. Beneyto/ J.A. García Amado, Tecnos, Madrid, 2019. 
Manfred E. STREIT; Werner MUSSLER, "The Economic Constitution of the European Community: From ‘Rome' to 'Maastricht'”, European Law Journal, vol. 1, núm. 1, marzo 1995, pp. 5-30.

Gunther TEUBNER, "Transnational Economic Constitutionalism in the Varieties of Capitalism”, The Italian Law Journal, núm. 1, 2015.

-, Constitutional Fragments. Societal Constitutionalism and Globalization, Oxford University Press, Oxford, 2012.

Kaarlo TUORI; Klaus TUORI, The Eurozone Crisis: A Constitutional Analysis, Cambridge University Press, Cambridge, 2013.

Uwe VOLKMANN, Elementos de una teoría de la Constitución alemana, trad. I. Gutiérrez Gutiérrez, Marcial Pons, Madrid, 2019.

Armin VON BOGDANDY; Jürgen BAST (eds.), Principles of European Constitutional Law, Hart, Oregon, 2010.

Armin VON BOGDANDY; Matthias GOLDMANN; Ingo VENZKE, "From Public International To International Public Law: Translating World Public Opinion Into International Public Authority", MPIL Research Paper Series, núm. 2, 2016.

Knut WOLFANG NÖRR, " Economic constitution»: On the roots of a legal concept", Journal of Law and Religion, vol. 11, núm. 1, 1994-1995.

Brigitte YOUNG, “Is Germany's and Europe's Crisis Politics Ordoliberal and/or Neoliberal?", en Thomas BIEBRICHER; Frieder VOGELMANN (eds.), The birth of austerity. Rowman Littlefield International, London-New York, 2017.

Ernest A. YOUNG, "The Constitution Outside the Constitution", The Yale Law Journal, núm. 117, 2007, pp. 408-47. 
